\title{
SELEÇÃO DE MICRORGANISMOS COM POTENCIAL DE PRODUÇÃO DE COMPOSTOS ALELOPÁTICOS PARA O CONTROLE DE PLANTAS DANINHAS
}

\author{
FLÁvio ANDRÉ MARTINS DA SILVA
}

\begin{abstract}
Dissertação apresentada à Escola Superior de Agricultura "Luiz de Queiroz", Universidade de São Paulo, para obtenção do título de Mestre em Agronomia, Área de Concentração: Fitotecnia.
\end{abstract}

P I R A C I C A B A

Estado de São Paulo - Brasil

Dezembro - 2004 


\title{
SELEÇÃO DE MICRORGANISMOS COM POTENCIAL DE PRODUÇÃO DE COMPOSTOS ALELOPÁTICOS PARA O CONTROLE DE PLANTAS DANINHAS
}

\section{FLÁVIo ANDRÉ MARTINS DA SILVA}

Engenheiro Agrônomo

Orientador: Prof. Dr. PEDRO JACOB CHRISTOFFOLETI

\begin{abstract}
Dissertação apresentada à Escola Superior de Agricultura "Luiz de Queiroz", Universidade de São Paulo, para obtenção do título de Mestre em Agronomia, Área de Concentração: Fitotecnia.
\end{abstract}

P I R A C I C A B A

Estado de São Paulo - Brasil

Dezembro - 2004 
Dados Internacionais de Catalogação na Publicação (CIP) DIVISÃO DE BIBLIOTECA E DOCUMENTAÇÃO - ESALQ/USP

Silva, Flávio André Martins da

Seleção de microrganismos com potencial de produção de compostos alelopáticos para o controle de plantas daninhas / Silva, Flávio André Martins da Silva. -- Piracicaba, 2004.

60 p. : il.

Dissertação (Mestrado) - - Escola Superior de Agricultura Luiz de Queiroz, 2005. Bibliografia.

1. Actinomiceto 2. Alelopatia 3. Herbicidas - Metabólitos secundários 4. Plantas daninhas I. Título

CDD 632.58

"Permitida a cópia total ou parcial deste documento, desde que citada a fonte - O autor" 


\section{DEDICATÓRIA}

À minha mãe Sueli Aparecida Yamasaki da Silva. 


\section{AGRADECIMENTOS}

Ao Prof. Dr. Pedro Jacob Christoffoleti pela confiança e oportunidade, pela orientação, exemplo de respeito, dedicação e méritos.

Ao Prof. Dr. Márcio Roberto Lambais pela coorientação, valiosas sugestões, comentários e fornecimento das condições necessárias ao desenvolvimento deste trabalho.

À Prof. Dr. Sônia Maria de Stéfano Piedade pela importante colaboração nas análises estatísticas dos resultados.

À Helena, Luiz Ferrari, Aparecido Mendes, Aparecido Serrano, Fernando, Denise e todos os técnicos e funcionários da Escola Superior de Agricultura "Luiz de Queiroz" - ESALQ que me assistiram, tendo eles essencial colaboração neste trabalho.

A todos os professores da Escola Superior de Agricultura "Luiz de Queiroz" - ESALQ, que tive a oportunidade de conhecer, por seus ensinamentos e contribuições.

Ao Conselho Nacional de Desenvolvimento Científico e Tecnológico $\mathrm{CNPq}$ pela bolsa de estudos concedida para a realização deste trabalho. 
À Carol que esteve sempre a meu lado, entusiasmando, ajudando e apoiando em todos os momentos.

Aos meus irmãos e a todos os meus amigos que sempre acreditaram no meu trabalho me dando motivação e perseverança.

Finalmente agradeço a DEUS pela minha vida. 


\section{SUMÁRIO}

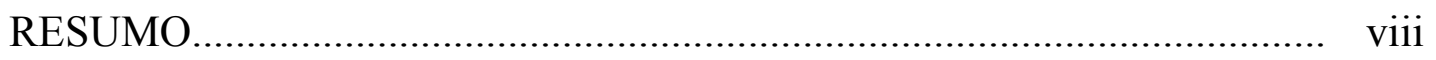

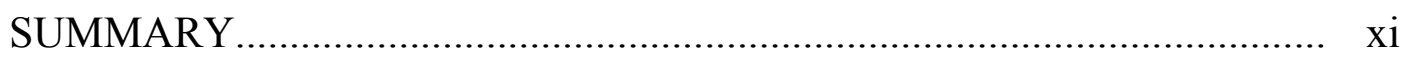

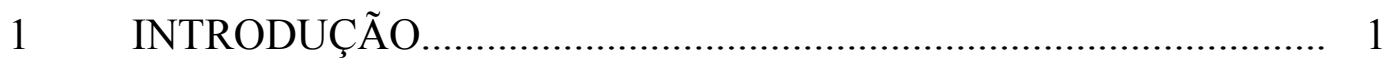

2 REVISÃO DE LITERATURA........................................................ 5

2.1 Histórico da utilização de produtos químicos como pesticidas na

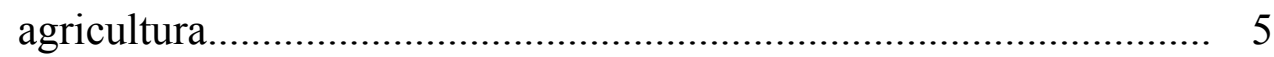

2.2 Estratégias de descoberta de novas moléculas.................................... 6

2.2.1 Por estrutura................................................................................... 8

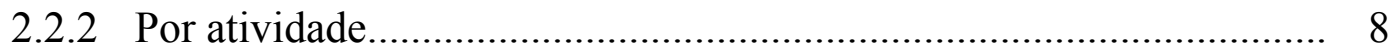

2.3 Descoberta de novos compostos naturais.......................................... 10

2.3.1 Escolha da fonte biológica............................................................... 10

2.3.2 Bioensaio - fracionamento e isolamento........................................... 11

2.4 Metodologias de isolamento de microrganismos potencialmente produtores de fitotoxinas............................................................. 12

2.5 Situação atual de pesquisa com fitotoxinas microbianas....................... 13

2.6 Limitações e pesquisas futuras............................................................. 16

3 MATERIAL E MÉTODOS....................................................... 19

3.1 Coleta de solos, isolamento de colônias e bioensaios de seleção (Screenings)........................................................................... 20

3.1.1 Coleta das amostras de solo para extração dos actinomicetos.............. 20

3.1.2 Isolamento dos actinomicetos........................................................... 21 
3.1.3 Screening primário - Teste de germinação.................................... 23

3.1.4 Screening secundário - Câmara-de-crescimento............................. 25

3.2 Teste do sobrenadante das culturas selecionadas nos screenings em condições de casa-de-vegetação..................................................... 27

$4 \quad$ RESULTADOS E DISCUSSÃO............................................. 31

4.1 Potencialidade dos diferentes sistemas de produção/vegetação......... 32

4.2 Efeito do meio de cultura no desenvolvimento das plântulas de pepino e sorgo .................................................................... 33

4.3 Screenings de seleção primário e secundário.................................. 35

4.4 Teste do sobrenadante das culturas selecionadas nos screenings em condições de casa-de-vegetação.................................................. 40

$5 \quad$ CONCLUSÕES................................................................. 51

REFERÊNCIAS BIBLIOGRÁFICAS................................................... 53 


\title{
SELEÇÃO DE MICRORGANISMOS COM POTENCIAL DE PRODUÇÃO DE COMPOSTOS ALELOPÁTICOS PARA O CONTROLE DE PLANTAS DANINHAS
}

\author{
Autor: FLÁVIO ANDRÉ MARTINS DA SILVA \\ Orientador: Prof. Dr. PEDRO JACOB CHRISTOFFOLETI
}

\section{RESUMO}

A agricultura moderna exige que as operações de manejo das plantas daninhas sejam economicamente viáveis, e principalmente seguras em termos de minimização da contaminação ambiental. A preocupação sobre a utilização intensiva de herbicidas sintéticos tem sido debatida constantemente, de tal forma que pesquisas têm sido desenvolvidas estrategicamente para a descoberta de novas moléculas herbicidas, baseadas em produtos naturais, para aplicação direta como agente de controle ou utilização indireta como aleloquímico. O solo é habitado por uma grande variedade de microrganismos, sendo que a maioria deles não foi estudada e identificada até o momento, conseqüentemente muitas pesquisas ainda podem ser desenvolvidas com o objetivo de explorar metabólitos secundários produzidos por estes microrganismos. Sendo assim, foi desenvolvida a presente pesquisa com o objetivo de testar e desenvolver uma fase inicial na seleção e descoberta de microrganismos do solo (actinomicetos) com potencial de produção 
de compostos fitoinibitórios. O método geral de seleção constituiu-se na coleta de amostras de solo de 0-20 cm de profundidade, a partir de áreas com diferentes sistemas de manejo e/ou vegetação. Estas amostras de solo foram então submetidas ao isolamento de actinomicetos (10 g de solo de cada amostra) através da diluição em série e plaqueamento em meio seletivo. Foram isoladas e cultivadas em meio líquido glicerina-caseína 103 colônias, sendo que, a solução de metabólitos acelular foi obtida por centrifugação e filtragem. A partir das soluções contendo os metabólitos foi conduzido um teste de germinação (screening primário) através de bioensaios de laboratório, utilizando como plantas teste pepino (Cucumis sativa) e sorgo (Sorghum bicolor). Com o objetivo de verificar a concentração do meio de cultura que exerceria o mínimo de efeito na germinação e crescimento/desenvolvimento das plântulas, foi realizado um teste de germinação com o meio de cultura sem os metabólitos microbiológicos, sendo avaliado através de análise de regressão dos resultados obtidos. O screening secundário foi realizado em condições de câmara-de-crescimento e consistiu na aplicação do meio de cultura acelular em condições de pré e pós-emergência das plantas de pepino e sorgo. Os screenings primário e secundário resultaram na seleção de sete microrganismos produtores de composto fitoinibitórios, estes utilizados para condução do experimento em condições de casa-de-vegetação, sendo aplicadas as soluções de metabólitos em condições de pré e pós-emergência das plantas de pepino, sorgo, picão-preto (Bidens pilosa) e capim colchão (Digitaria ciliaris). A conclusão principal desta pesquisa foi de que o método para seleção de isolados de actinomicetos, com potencial de produção de fitotoxicinas é adequado, e pode ser utilizado em um programa de descoberta de novos compostos com potencial herbicida, no entanto, os resultados obtidos não permitiram isolar actinomicetos com suficiente potencial fitoinibitório, para ser 
utilizado de forma direta em um programa de manejo de plantas daninhas na agricultura. 


\title{
SELECTION OF MICROORGANISMS WITH POTENTIAL PRODUCTION OF ALLELOPATHIC COMPOUNDS FOR WEED CONTROL
}

\author{
Author: FLÁVIO ANDRÉ MARTINS DA SILVA \\ Adviser: Prof. Dr. PEDRO JACOB CHRISTOFFOLETI
}

\section{SUMMARY}

The modern agriculture requires that the weed management practices are economically feasible, and mainly safe for the minimization of the environmental contamination. The concern on the intensive use of synthetic herbicides has been debated constantly, in such way that researches have been developed strategically for the discovery of new herbicides molecules, based on natural products, either for direct application as control agent, or for indirect use as allelochemical. The soil is colonized by a great variety of microorganisms, however most of them were not studied and identified at the moment, consequently many researches still can be done, with the objective of exploring secondary metabolites produced by these microorganisms. Therefore, it was developed this research with the objective of testing and developing a initial process in the selection and discovery of soil microorganisms (actinomycetes) with potential of producing phytoinhibitory compounds. The general method used 
in the research consisted of soil sampling at 0-20 $\mathrm{cm}$ depth, from areas that had been cultivated with different cropping systems and/or vegetation. These soil samples were submitted to actinomycets isolation (10 $\mathrm{g}$ of soil per sample) through series dilution in selective medium. It was isolated and cultivated in liquid casein-glycerin medium 103 colonies, being the no cellular metabolite solution obtained by centrifugation and filtration. From the solutions containing the metabolites it was conducted a germination test (primary screening) through a laboratory bioassay with test plants of cucumber (Cucumis sativus) and sorghum (Sorghum bicolor). Objectifying to verify each of the cultivation medium concentrations that would cause the minimum effect on germination and growth/development of seedlings, it was also conducted a germination test with medium without the microbial metabolites, being evaluated through regression analysis results. The secondary screening was done in the growth chamber conditions, and consisted of application of no cellular medium in pre and post emergence conditions of the plants of sorghum and cucumber. The primary and secondary screening resulted in the selection of seven microorganisms producers of phytoinhibitory compounds, these used to conduct an experiment in the greenhouse, being sprayed the metabolic solutions in pre and post emergence conditions of cucumber, sorghum, Bidens pilosa and Digitaria ciliaris. The main conclusion of the research was that the method used for actinomycets selection and isolation, with potential of phytotoxins production is adequate and can be used in a new compounds discovery program with potential herbicide effects; however the results obtained did not allow isolating actinomycets with enough phytoinhibitory potential to be directly used in a program of weed management in agriculture. 


\section{INTRODUÇÃO}

As plantas daninhas são definidas como plantas que ocorrem em local e momento onde elas são indesejáveis às atividades humanas. Sendo assim, a definição do termo planta daninha terá sempre um caráter antropomórfico, ou seja, a indesejabilidade das plantas daninhas está diretamente relacionada com as atividades e interesses humanos. Sempre que o ambiente é manipulado pelo homem para a prática da agricultura, surgem nichos ecológicos, que não são ocupados pelas culturas, e que podem ser eventualmente habitados pelas plantas daninhas. Estas plantas afetam a produção agrícola, florestal, animal e até a saúde humana de forma significativa. O impacto econômico resultante das interferências negativas causadas pelas plantas daninhas na agricultura implica na necessidade da adoção de medidas de manejo. Estas por sua vez implicam em impactos econômicos, sociais e ambientais, sendo este último a maior preocupação da sociedade nos dias atuais.

A maioria das pesquisas desenvolvidas pela comunidade científica da Ciência das Plantas Daninhas objetiva o manejo racional e sustentável nos agroecossistemas. No entanto, a principal estratégia de manejo das plantas daninhas na agricultura moderna é através da aplicação de herbicidas orgânicos sintéticos, que constituem uma ferramenta valiosa para o controle de plantas daninhas, porém a utilização intensiva e/ou incorreta de herbicidas pode representar implicações negativas ao ambiente, à saúde humana e animal, além de 
representar uma parcela significativa dos custos de produção, da pressão de seleção de espécies de plantas daninhas tolerantes e do surgimento de biótipos resistentes dentro das populações.

Métodos alternativos de manejo de plantas daninhas devem ser utilizados em conjunto com os herbicidas sintéticos para que, de uma forma sustentável, estas plantas sejam controladas na agricultura. Dentre estes métodos alternativos destacam-se métodos supressivos da infestação, tais como culturas que apresentam alta habilidade competitiva, rotação de culturas, culturas intercalares, culturas de cobertura, cobertura vegetal morta, solarização, etc. No entanto, Hall et al. (2000) ressaltaram que a investigação na descoberta de produtos naturais para o manejo de plantas daninhas tem um grande potencial para o desenvolvimento de uma agricultura sustentável, e principalmente para a implementação de novas estratégias de controle das plantas daninhas. Pesquisas com produtos naturais podem resultar na descoberta de novos produtos químicos para aplicação direta como agentes de controle ou para sua utilização indireta como aleloquímicos.

A seleção de compostos da fermentação microbiológica, na área da pesquisa farmacêutica, tem sido feita freqüentemente durante as últimas décadas. Estes estudos têm levado pesquisadores a descoberta de novas drogas, com novas aplicações, mais notavelmente na área de antibióticos. A incorporação destas técnicas na área de agroquímicos é recente, e alvo de muitos debates. O que não se discute é a extraordinária capacidade que os microrganismos têm de produzir metabólitos secundários com diferentes estruturas. Nos testes de seleção das atividades de fermentados microbiológicos podem ser observadas atividades biorreguladoras e/ou fitotóxicas entre outras. Embora estratégias de descoberta de novos herbicidas baseados em produtos naturais não têm resultado em um número 
expressivo de sucessos como para outros pesticidas e produtos farmacêuticos, têm sido observadas notáveis descobertas que resultaram em sucesso (Duke et al., 2000a).

Para uma substância natural fitotóxica proveniente de microrganismo ter potencial de uso no controle de plantas daninhas é essencial que seja biodegradável, tenha mecanismo de ação específico a processos fisiológicos e/ou metabólicos e atue seletivamente (Stonard \& Miller-Wideman, 1995), embora esta última característica não se aplica para substâncias de ação total sobre as plantas daninhas. No entanto, estas características também podem ser vistas de maneira negativa; por exemplo, insuficiente estabilidade ambiental para proporcionar efeito residual de controle, e também menor espectro de ação que o desejável. Embora existam barreiras na produção e comercialização de produtos naturais, o sucesso na produção de metabólitos secundários tais como avermectina, fosfinotricilalanil-alanina e estrobilurina servem como justificativa para o contínuo estudo das potencialidades destes microrganismos e dos seus compostos metabólicos (Stonard \& Miller-Wideman, 1995).

Com o recente crescimento da biotecnologia, o interesse em microrganismos como fonte potencial na produção de herbicidas naturais vem crescendo. Os produtos de origem biológica têm uma grande vantagem em relação aos compostos de origem sintética, pois através da biotecnologia é possível acessar genes que codificam enzimas capazes de produzir e inativar estes produtos naturais. A tecnologia de transformação das culturas geneticamente modificadas, para expressar estes genes, representa um excelente meio para ressaltar a atividade dos herbicidas naturais, bem como é possível melhorar a seletividade destes produtos naturais para as culturas. 
Até o momento poucos trabalhos de pesquisa foram desenvolvidos no Brasil no sentido da procura de compostos naturais produzidos por microrganismos. Desta forma, o presente trabalho foi conduzido com o objetivo principal de testar e desenvolver uma fase inicial na seleção e descoberta de microrganismos do solo (actinomicetos) que têm potencial para o desenvolvimento de compostos naturais fitoinibitórios. 


\section{REVISÃO DE LITERATURA}

\subsection{Histórico da utilização de produtos químicos como pesticidas na agricultura}

A aplicação de produtos químicos naturais ou sintéticos como pesticidas é uma técnica utilizada desde os tempos remotos da prática da agricultura. Existem registros do uso de enxofre no controle de pragas em 1000 a.C., do uso dos resíduos da extração e do refinamento do azeite de oliva para o controle de plantas daninhas em 470 a.C. e de que os romanos aplicavam sal de cozinha (cloreto de sódio) nos campos agrícolas de seus inimigos como forma de punição, pois assim nenhum tipo de planta crescia (Zimdahl, 1991). Em 1865 surgiu na França a calda bordaleza, sendo extensivamente utilizada até hoje pelos agricultores no controle doenças de plantas. O primeiro composto orgânico destinado ao controle de plantas daninhas foi introduzido em 1932 (2-metil-4, 6dinitrofenol). No entanto, o uso extensivo de herbicidas sintéticos orgânicos na agricultura iniciou-se efetivamente durante a década de 40 quando foi descoberta a atividade herbicida do 2,4-D (Harrison \& Loux, 1995).

A agricultura mundial tem aplicado insumos intensivamente. $\mathrm{O}$ consumo de produtos químicos em 1997 foi avaliado em 26 bilhões de dólares norte-americanos por ano, sendo 46\% destes em herbicidas (FAO, 1997). Desde sua adoção nos sistemas de produção agrícola os herbicidas tornaram-se a 
principal ferramenta dos programas de controle de plantas daninhas, e dentre as razões desta utilização intensiva apontadas por Coble (1996) e Menendez \& De Prado (1998) destacam-se: o amplo espectro de controle, fácil aplicação, relação custo/benefício favorável, e versatilidade agronômica. No Brasil, as vendas de pesticidas de uma maneira geral em 2003 superaram os 3 bilhões de dólares norteamericanos, dos quais 50\% foram herbicidas (Sindag, 2004). Na cultura da soja foi onde a maior parte dos herbicidas foi aplicado, acumulando mais de $50 \%$ das vendas de produtos no país. No entanto, as pressões econômicas, sociais e ecológicas para limitar o uso de defensivos agrícolas nos sistemas de produção agrícola estão impulsionando a pesquisa em busca de procedimentos alternativos, que provoquem menor impacto ambiental e social (Severino, 2001). Desta forma, a busca de alternativas naturais de manejo de plantas daninhas é sem dúvida um dos caminhos alternativos para a pesquisa atual.

\subsection{Estratégias de descoberta de novas moléculas}

Atualmente o aperfeiçoamento dos equipamentos de pesquisa conferiu considerável redução do custo no isolamento e identificação de compostos naturais, quando comparado com a década passada. Isto causou interesses renovados nos produtos naturais em programas de descobertas de herbicidas. Outro motivo para interesse em fitotoxinas naturais é que elas oferecem a possibilidade de descoberta de novos mecanismos/sítios de ação de herbicidas (Duke et al. 2000b, 2000c) (Tabela 1). Mesmo que a fitotoxina seja inadequada para utilização comercial, a identificação de novos mecanismos de ação pode ser valiosa na produção de herbicidas sintéticos, com natureza química semelhante porém mais adequados para utilização na agricultura. 
Tabela 1. Sítios de ação de produtos naturais altamente fitotóxicos (Duke et al. 2002)

\begin{tabular}{|c|c|}
\hline Composto & Sítio de ação ${ }^{a}$ \\
\hline $\begin{array}{l}\text { AAL-toxina (toxina da } \\
\text { Alternaria alternata) }\end{array}$ & Ceramida sintase \\
\hline Actinonina & Peptídeo deformilase \\
\hline Brefeldina & Função do complexo de Golgi \\
\hline Coformicina carbocíclica & Adenosina monofosfato deaminase \\
\hline Cerulenina & 3-quetoacil-acil proteína sintase \\
\hline Coclioquinonas & Nicotinamida adenina dinucleotídeo reductase \\
\hline Coronatina & Antagonista do ác. jasmônico \\
\hline 1,4-cineole & Asparagina sintase \\
\hline Fisherelina & Proteína D-1 do fotossistema II \\
\hline Fumonisina & Ceramida sintase \\
\hline Fusicoccina & $\begin{array}{l}\text { Adenosina trifosfatase (ATPase) da membrana } \\
\text { plasmática }\end{array}$ \\
\hline Gabaculina & Algumas transaminases \\
\hline Gostatina & Aspartato amino transferase \\
\hline Grandinol & Proteína D-1 do fotossistema II \\
\hline Hydantocidina & Adenilosucinato sintase \\
\hline Leptospermone & 4-Hidroxifenilpiruvato dioxigenase \\
\hline Faseolotoxina & Ornitina carbamoiltransferase \\
\hline Fosfinotricina & Glutamina sintase \\
\hline Podofilotoxina & Tubulina \\
\hline Prehelmintosporol & ATPase da membrana plasmática \\
\hline Piridazocidina & Fotossistema I \\
\hline Quassinóides & $\begin{array}{l}\text { Nicotinamida adenina dinucleotídeo fosfato } \\
\text { oxidase? }\end{array}$ \\
\hline Rizobitoxina & $\beta$-Cistationase \\
\hline Tagetitoxina & RNA polimerase \\
\hline Sorgoleone & Proteína D-1 do fotossistema II \\
\hline Siringotoxina & ATPase da membrana plasmática \\
\hline Tentoxina & $\mathrm{CF}_{1}$ ATPase do cloroplasto \\
\hline Tricolorina A & ATPase da membrana plasmática \\
\hline Tiolactomicina & Acetil-CoA transacilase \\
\hline Ácido úsnico & 4-Hidroxifenilpiruvato dioxigenase \\
\hline
\end{tabular}

${ }^{a}$ Sítios de ação em itálico são compartilhados com herbicidas sintéticos. 


\subsubsection{Por estrutura}

Sabe-se que certas estruturas químicas afetam mais facilmente um sítio de ação particular do que outros. Assim, compostos aos quais as estruturas são similares às estruturas de fitotoxinas, ou inibidores de uma enzima, ou de funções da planta, podem ter uma atividade similar. Por exemplo, o ácido úsnico, produto secundário de alguns liquens, é estruturalmente similar à classe herbicida das triquetonas, que são inibidores da HPPD. Romagni et al. (2000) descobriram que o ácido úsnico (figura 1) é um melhor inibidor da HPPD in vitro do que os sulcotrione. Produtos naturais, que são análogos estruturais de metabólicos intermediários ou co-fatores enzimáticos, poderiam ser inibidores de enzimas que usam estes intermediários ou co-fatores. Por exemplo, AAL-toxina (uma toxina da Alternaria alternata) (figura 1) é um análogo do substrato base da ceramida sintase, e este é um potente inibidor desta enzima (Abbas et al. 1996 e Abbas et al., 2002). O açúcar análogo 2,5 anidro-d-glucitol é fitotoxico (figura 1) (Tanaka et al. 1996) por causa da similaridade estrutural com a frutose (Dayan et al. 2002). Esta protoxina é fosforilada pela enzima hexoquinase e fosfofrutoquinase, produzindo o bisfosforilado análogo a frutose-1,6-bis-fosfato. Uma vez bioativado, este açúcar análogo fosforilado inibe a frutose-1,6-bisfosfato aldolase.

\subsubsection{Por atividade}

Alguns compostos naturais têm sido testados para alguns tipos de atividades biológicas que não herbicídicas. Se esta atividade biológica é conhecida, então ela pode ser usada para predizer uma fitotoxicidade e mecanismo de ação como herbicida. Por exemplo, actinonina (figura 1) é conhecido como uma nova classe de potentes antibióticos com um único mecanismo de ação, 
inibição do peptídeo deformilase (Chen et al. 2000). Dirk et al. (2001) descobriram que sua fitotoxicidade é causada pelo mesmo mecanismo de ação.

Outro exemplo é o das fumonisinas (figura 1), estes compostos foram conhecidos primeiro por serem tóxicos aos animais, inibindo a ceramida sintase (Abbas et al. 1996). Fumonisinas e compostos estruturalmente correlatos apresentam extrema fitotoxicidade pelo mesmo mecanismo (Abbas et al. 1994).

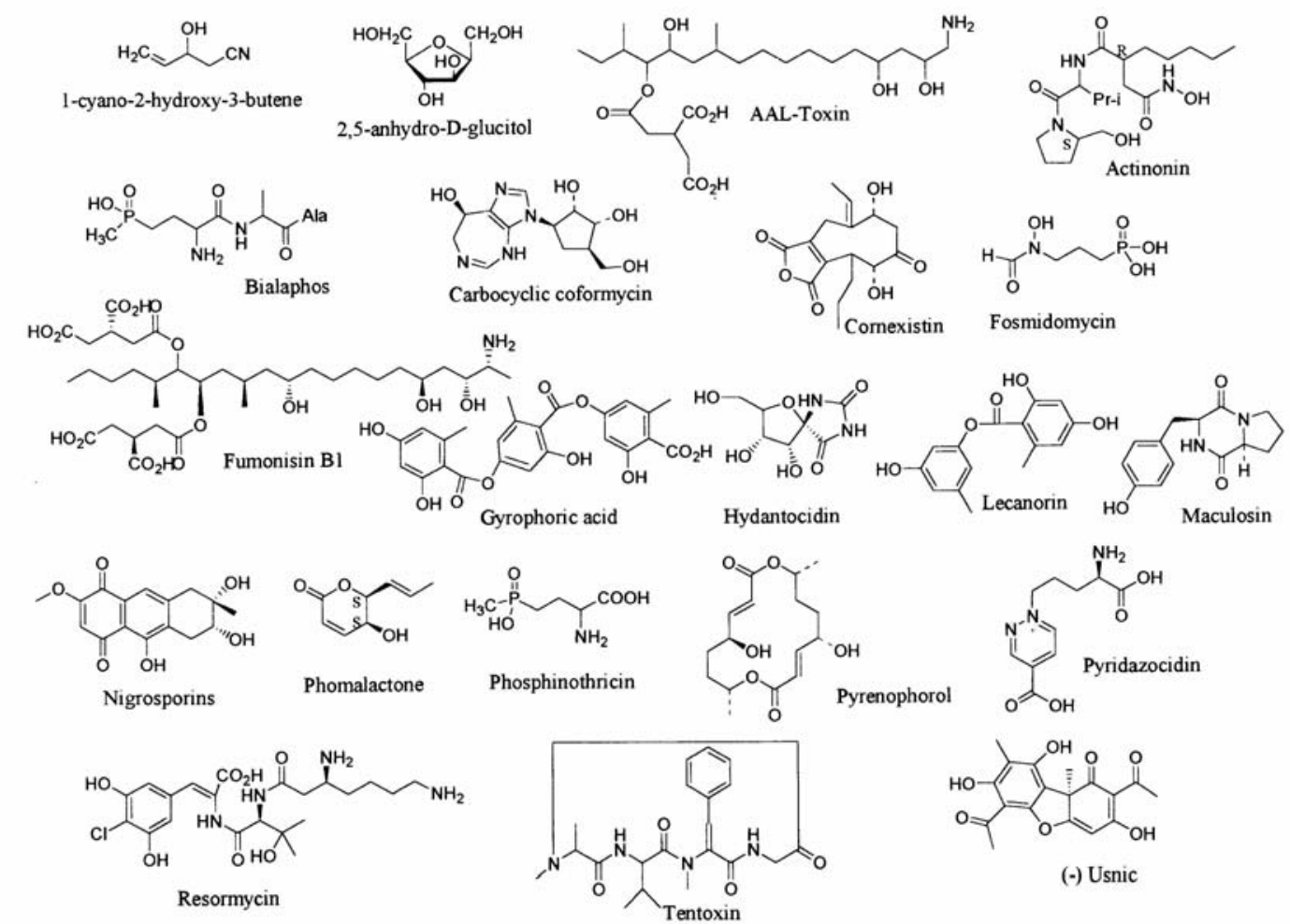

Figura 1 - Estruturas de alguns compostos produzidos por microrganismos (Duke et al. 2002) 


\subsection{Descoberta de novos compostos naturais}

\subsubsection{Escolha da fonte biológica}

Menos de 1\% dos microrganismos que habitam o solo foram cultivados e identificados até o momento (Felske et al. 1997; Pimm et al. 1995), sendo que os microrganismos do solo têm capacidade de produção de inúmeros compostos secundários. Desta forma, supõe-se que ainda exista uma vasta quantidade de compostos secundários a serem descobertos. Em algumas indústrias, que pesquisam a descoberta de novos compostos químicos para a agricultura, os microrganismos de solo são estudados como fonte de produtos naturais com atividade e potencial de defensivos agrícolas, e dentre estas atividades a herbicida. Duas estratégias têm sido utilizadas para a descoberta destas substâncias: (1) isolamento e cultivo de microrganismos do solo, principalmente de locais exóticos, e (2) manipulação das condições de cultivo dos microrganismos. Não é certo que as condições de cultivo de microrganismos usadas no laboratório são adequadas para a produção de todos os compostos secundários que eles produzem na natureza (Duke et al. 2002).

Outra estratégia para a descoberta de fitotoxinas está baseada na ecologia química dos microrganismos. Esta técnica está dirigida para estudo dos microrganismos, que por alguma razão acredita-se produzir fitotoxinas. $\mathrm{O}$ caso mais óbvio é o de patógenos de plantas (Sugawara 2000). Por exemplo, maculosina (Figura 1) é produzida pela Alternaria alternata, que infecta a Centaurea maculosa Lam. (Bobylev et al. 1996). É importante ressaltar que somente alguns fitopatógenos produzem fitotoxinas suficientes para matar as células da plantas antes de utilizá-las como fonte de alimentos. 


\subsubsection{Bioensaio - fracionamento e isolamento}

Uma vez que uma fonte biológica de fitotoxina é encontrada, esta normalmente produz um complexo de substâncias as quais devem ser fracionadas em componentes e compostos bioativos (Duke et al. 2000a, 2000b, 2000c). O fracionamento geralmente consiste inicialmente em separar extratos de uma fonte biológica identificada entre solventes polares e não-polares. Alíquotas são testadas para a atividade biológica (ex. fitotoxicidade), e o fracionamento continua na porção que demonstrar a bioatividade. A cromatografia geralmente é o próximo passo, subfrações são coletadas e testadas até que um composto puro é obtido. Este processo tem, em muitas vezes, resultado positivo na descoberta de moléculas bioativas de plantas medicinais (Choudharry \& Atta-ur-Rahman 1997; Pezzuto et al. 1998). Embora esta prática ainda é limitada na descoberta de pesticidas, o isolamento de um alcalóide com atividade nematicida (Choudharry \& Atta-ur-Rahman 1997), e fitotoxinas do sorgo [Sorghum bicolor (L.) Moench] (Rimando et al. 1998), do Leucophyllum frutescens (Rimando et al. 1999) e do Fusarium solani (Tanaka et al. 1996) têm sido realizado utilizando esta técnica.

$\mathrm{O}$ isolamento guiado pela bioatividade está se tornando um processo automatizado, onde modernos equipamentos são construídos para permitir o fracionamento dos eluentes. Quando os picos são detectados, a partir dos extratos injetados em um cromatógrafo líquido de alta performance, uma porção de cada um é coletada e divergida para análise estrutural por massa (Constant \& Beecher 1995) ou por um espectrômetro de ressonância magnética nuclear (Lindon et al. 1996). A instrumentação analítica completamente automatizada, composta com autoamostrador para coleta de frações para bioensaio, reduz grandemente o tempo e esforços necessários para isolamento de compostos conhecidos, enquanto também maximiza a chance para identificar novos compostos químicos com 
atividade biológica específica (Hook et al. 1997). O poder de uma instrumentação totalmente automatizada e integrada foi demonstrado na identificação do 5nitropiridone e outros metabólitos do milho (Bailey et al. 2000). A descoberta de herbicidas naturais será facilitada utilizando instrumentações completamente automatizadas, tais como cromatografia líquida - espectrometria de massa (LC/MS) e cromatografia líquida - espectrometria de massa - ressonância magnética nuclear (LC/MS/NMR).

\subsection{Metodologias de isolamento de microrganismos potencialmente produtores de fitotoxinas}

No passado, as pesquisas que tinham como objetivo a descoberta de produtos microbiológicos naturais com atividade fitotóxica eram constituídas de testes de inibição da germinação de sementes ou da observação do efeito em plantas pulverizadas com a solução teste. Mais recentemente, bioensaios procurando selecionar produtos que apresentam ação específica em certas reações metabólicas ou sítios específicos de ação têm sido desenvolvidos. Uma discussão dos principais tipos de bioensaios na descoberta e purificação de metabólitos secundários herbicidicamente ativos pode ser encontrada em Stonard \& MillerWiderman (1995).

Dentre as metodologias descritas por Stonard \& Miller-Widerman (1995) destacam-se: ensaios com plantas inteiras, partes de folhas e algas, inibição da germinação, coleoptilo de trigo, screening na forma de matriz, suspensão de células e calos, inibição da fotossíntese, enzimas e antimetabólitos e translocação. Para o presente trabalho foi adotada uma combinação de metodologias. 


\subsection{Situação atual de pesquisa com fitotoxinas microbianas}

O desenvolvimento tecnológico-científico mais significativo na questão dos herbicidas naturais de fermentação microbiana ocorreu quando Bayer et al. (1972) descobriram o metabólito fosfinotricilalanil-alanina produzido por Streptomyces hygroscopicus. Desde então, muitos compostos herbicidas produzidos por microrganismos têm sido descobertos, entre eles: herbicidina A e B, herbimicina A e B, anisomicina e toyocamicina. Dois derivados de aminoácidos foram descobertos à partir de actinomicetos e atualmente são recomendados e comercialmente utilizados como herbicidas: $\mathrm{N}$-\{4-[Hidroxi (metil) fosfinoil] homoalanil $\}$-alanilalanina (bialaphos) e ácido DL-Homoalanina4-il (metil) fosfínico (glufosinato).

DeFrank \& Putnam (1985) testaram actinomicetos provenientes de nove amostras de solos coletadas de diferentes locais para avaliar o potencial destes microrganismos produzir compostos secundários com atividade herbicida. Após o isolamento, 20 sementes de Echinochloa crusgalli (capim-arroz) e 10 sementes de Cucumis sativus L. (pepino) foram parcialmente inseridas em meio contendo agar. Oito dos 120 isolados produziram substâncias capazes de inibir mais de $60 \%$ da germinação comparado ao controle; 21 isolados reduziram de 5 a $20 \%$ o crescimento em relação ao controle. No mesmo experimento, dois isolados que se mostraram com bom potencial fitotóxico foram escolhidos para avaliar a capacidade de produzir toxinas em cultura submersa. Destes dois isolados, apenas um apresentou inibição significativa da germinação e do crescimento.

Heisey et al. (1985) estudaram microrganismos com atividades herbicidas isolados à partir de varias amostras de solo coletadas nos estados de Michigan, Pensilvânia e Califórnia. Actinomicetos foram então selecionados e 
isolados, e para testar as atividades herbicídicas dos compostos produzidos pelos microrganismos, 50 sementes de Cucumis sativus L., 20 sementes de Echinochloa crusgalli e 20 sementes de Lepidum sativum L. foram distribuídas de maneira eqüidistante em placas de petri contendo o cultivo dos isolados. Alguns microrganismos que mostraram considerável inibição foram testados para produção de fitotoxinas em meio líquido. De um total de 347 isolados testados 10 a $12 \%$ reduziram o crescimento das plântulas com inibição pronunciada, sendo que, a maioria dos isolados teve pequeno ou nenhum efeito sobre o crescimento das plântulas (69 a 87\%). O número de isolados que estimularam o crescimento foi de 19\% em C. sativus L., 10\% em E. crusgalli e 2\% em L. sativum L. Neste estudo foi também comparada a produção de fitotoxinas entre meios sólidos e líquidos de cultivo de microrganismos, sendo observada uma alta correlação entre a produção de toxinas no meio sólido com a do meio líquido. Quase todos os isolados cultivados no meio sólido que inibiram o crescimento das plântulas também o fizeram quando cultivados em meio líquido.

Heisey \& Putnam (1986) avaliaram a atividade herbicídica de compostos antibióticos produzidos por uma raça selvagem de Streptomyces higroscopicus. Para o bioensaio foi utilizada a planta daninha Lepidium sativum L. através de 10 sementes em cada repetição sendo a avaliação feita medindo-se o comprimento da radícula transformado em porcentagem da medida do controle. Foi verificado que a atividade biológica tornou-se aparente após 3 dias da incubação, o pico ocorreu entre 7-11 dias e declinou logo após. Os compostos fitotóxicos na concentração de $21 \mu \mathrm{L}$ por placa causaram uma redução de $50 \%$ no crescimento da radícula $\left(\mathrm{ID}_{50}\right)$, comparado com o controle. A quase completa inibição ocorreu com uma dose de $60 \mu \mathrm{L}$. 
Produtos naturais com potencial fitotóxico podem ser derivados diretamente de plantas, como o cinmethylin, leptospermone e artimisinin e seus derivados (Duke et al. 2000a). O exemplo mais recente de sucesso de compostos derivados de plantas é o herbicida mesotrione, utilizado comercialmente no controle de plantas daninhas em pós-emergência na cultura do milho. No entanto, é a partir de microrganismos que as pesquisas de descoberta de fitotoxinas têm tido maior sucesso. Fitotoxinas produzidas a partir de microrganismos apresentam diversas vantagens em relação a aleloquímicos provenientes de plantas superiores (Duke 1997). Os aleloquímicos de plantas superiores normalmente têm pequena seletividade e, em muitos casos, são autotóxicos para a espécie produtora. Também, muitos têm pequena eficácia de fitoinibição, quando comparado com as toxinas microbiológicas. Assim, os pesquisadores têm concentrado grandes esforços no isolamento de fitotoxinas de origem microbiológica.

Os actinomicetos, microrganismos unicelulares, taxonomicamente classificados entre as bactérias e os fungos (Waksman, 1950), têm sido o tipo de microrganismo estudado com maior freqüência como fonte de produção de produtos naturais com ação herbicídica, pois eles produzem uma grande variedade de antibióticos e possivelmente produtos com ação fitoinibitória. Estes microrganismos são abundantes em solos, principalmente naqueles em que o teor de matéria orgânica é abundante (Heisey et al., 1985).

Mishra et al. (1988) estudaram 796 isolados de actinomicetos aeróbios, representando 19 gêneros. Deste total, 66 isolados apresentaram efeito fitotóxico em plantas de Echinochloa crusgalli (monocotiledônea) e 35 inibiram a germinação de Lepidium sativum (dicotiledônea). O gênero de actinomiceto que apresentou maior porcentagem de isolados fitotóxicos foi o Streptomyces com $18 \%$ dos isolados sendo fitotóxicos à planta daninha Lepidium sativum. Outros 
gêneros que apresentaram boa porcentagem de isolados com potencial fitotóxico nesse trabalho foram Actinomadura, Actinoplanes e Nocardiopsis.

Estas evidências indicam que os actinomicetos são os microrganismos com maior probabilidade para serem produtores de compostos naturais com atividade fitotóxica, e portanto foram utilizados na presente pesquisa.

\subsection{Limitações e pesquisas futuras}

Nesta revisão têm sido descritos casos de benefícios e sucessos da utilização de produtos naturais como herbicidas ou da descoberta de novos herbicidas. Desta forma, questionamos porque poucas pesquisas têm sido conduzidas por estas técnicas. Dentre as razões apontadas para o desinteresse científico, destaca-se que alguns produtos naturais não têm viabilidade econômica para serem utilizados comercialmente como defensivos agrícolas por causa de sua estrutura química complexa. Por exemplo, o tentoxin (figura 1), um tetrapeptídeo cíclico, é um excelente herbicida, mas sua produção é muito onerosa. Consideráveis pesquisas de estrutura-atividade para encontrar uma molécula análoga mais barata e com atividade similar foram conduzidas por Bland et al. 1993 e Edwards et al. 1988 porém sem grande sucesso. Dentre as explicações para a dificuldade de encontrarem-se análogos é que a estrutura do composto natural já pode ter sido otimizada pela natureza no processo de adaptação. Em tais casos, se a estrutura é complexa, tentativas para gerar uma molécula de baixo custo podem não ter sucesso.

Outro fator considerado pelos pesquisadores que trabalham na descoberta de fitotoxinas é que, embora a mídia popular enfatiza ao público o conceito herbalista medieval de que tudo na natureza é saudável, muitos dos 
compostos mais tóxicos para humanos conhecidos são naturais (ex. aflatoxina, fumonisinas, ricina). Alguns produtos naturais fitotóxicos também são altamente tóxicos à mamíferos, por exemplo, a AAL-toxina é completamente tóxica às células de mamíferos (Abbas et al. 1996). Este aspecto prejudica o interesse por pesquisas em algumas fitotoxinas naturais para o controle de plantas daninhas.

Não obstante, do ponto de vista toxicológico-ambiental, a meia-vida curta dos produtos naturais é uma característica favorável para herbicidas residuais provenientes de fitotoxinas, mas agronomicamente um herbicida deve persistir no ambiente tempo suficiente para que tenha o efeito desejado durante o período crítico de competição entre as plantas daninhas e as culturas. Trabalhos de pesquisa têm demonstrado que, em alguns casos, herbicidas naturais não persistem no ambiente o suficiente para serem efetivos (Schrader et al. 2000).

A propriedade intelectual associada à organismos de lugares exóticos têm complicado muito a condução das pesquisas pelos países que estão mais aptos à desenvolve-las. Países em desenvolvimento têm tido suas fontes biológicas exploradas por instituições de países desenvolvidos para a descoberta de medicamentos e outros produtos de propriedades diversas, inclusive de defensivos agrícolas. Isto resulta na elaboração de leis para reter algum nível de proteção à propriedade de compostos de organismos naturais destes países. Em alguns casos isto tem desencorajado os esforços de pesquisas que usam a diversidade biológica de certos lugares.

Até recentemente o custo do isolamento de compostos e da elucidação de estruturas era muito alto. Este problema juntamente com a redescoberta de compostos conhecidos é desanimador (Ayer et al. 1989 e Heisey et al. 1988). No entanto, instrumentações laboratoriais modernas tais como: cromatógrafo líquido, 
espectrômetro de massa e ressonância magnética nuclear, somadas a automação foram importantíssimas na redução do tempo e do esforço necessário para identificar e isolar compostos. Sendo assim, nos últimos anos pesquisas na descoberta de produtos naturais têm sido a tônica de muitos pesquisadores, inclusive projetos de pesquisa relacionados com a descoberta de fitotoxinas.

Produtos naturais podem requerer procedimentos menos complicados para o seu registro, reduzindo o custo de desenvolvimento do produto até sua comercialização. Outra razão para o interesse em fitotoxinas naturais é que elas oferecem novos sítios de ação (tabela 1). Nas últimas duas décadas não foi descoberto nenhum novo mecanismo de ação de herbicidas, portanto o potencial de descoberta de novos produtos que atuem em sítios de ação diferenciados abre uma nova perspectiva para o controle químico de plantas daninhas. Sendo assim, uma fitotoxina mesmo que não seja apropriada para o uso comercial, pode ser muito valiosa na identificação de um novo sítio de ação e no design de novos herbicidas sintéticos.

Apesar das dificuldades enfrentadas pelos projetos de pesquisa que buscam a descoberta de fitotoxinas naturais, atualmente a pressão por novos produtos com diferentes mecanismos de ação justifica esforços científicos no sentido de identificar microrganismos potenciais produtores de fitotoxinas. Estes microrganismos poderão no futuro ser estudados de forma detalhada e seus compostos isolados e sintetizados. Sendo assim, foi desenvolvida a presente pesquisa com o objetivo de selecionar microrganismos com potencial de produção de fitotoxinas em condições brasileiras, onde até o momento não existem pesquisas voltadas para seu isolamento, seleção e identificação. 


\section{MATERIAL E MÉTODOS}

O protocolo geral seguido nesta pesquisa para seleção de microrganismos potencialmente produtores de fitotoxinas segue uma adaptação dos procedimentos encontrados na literatura, procurando fazer modificações que viabilizassem o desenvolvimento da pesquisa. Na figura 2 pode ser observado o diagrama resumido de todo o procedimento utilizado.

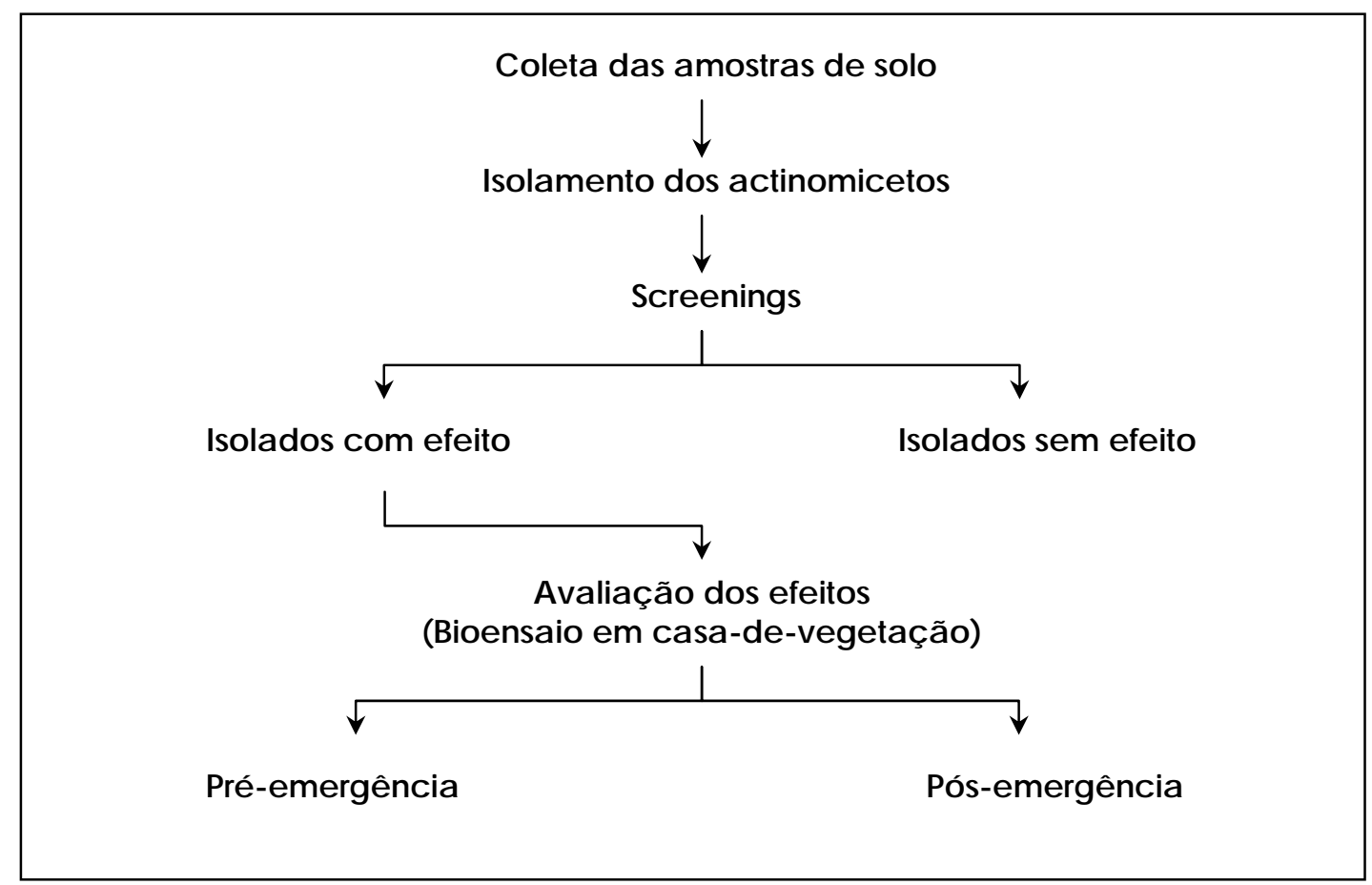

Figura 2 - Diagrama mostrando o protocolo seguido para a seleção de microrganismos potencialmente produtores de compostos fitotóxicos 


\subsection{Coleta de solos, isolamento de colônias e bioensaios de seleção (Screenings)}

\subsubsection{Coleta das amostras de solo para extração dos actinomicetos}

Com o intuito de obter nos experimentos elevada diversidade microbiana, foram coletadas amostras de solo sob diferentes sistemas de manejo e/ou vegetação em áreas experimentais da Escola Superior de Agricultura "Luiz de Queiroz" - Universidade de São Paulo, município de Piracicaba - SP (altitude de $560 \mathrm{~m}$, latitude de $22^{\circ}$ e $45^{\prime} \mathrm{S}$ e longitude de $47^{\circ}$ e $38^{\prime} \mathrm{W}$ ). O clima da região é do tipo Cwa, segundo a classificação de Koeppen, isto é, clima mesotérmico, úmido, subtropical com inverno seco. De acordo com o Departamento de Ciências Exatas da ESALQ/USP, a temperatura média do mês mais quente está acima de $24^{\circ} \mathrm{C}$ e a do mês mais frio abaixo de $17^{\circ} \mathrm{C}$, apresentando uma precipitação pluvial média anual de $1200 \mathrm{~mm}$.

A descrição da vegetação e/ou do sistema de manejo que ocorriam na área dos locais amostrados estão citados a seguir. Entre parênteses está a denominação resumida do local, sendo esta utilizada em todo o texto.

a. Mata virgem com superfície coberta de serrapilheira (matavirgem).

b. Floresta implantada com pinus (Pinus taeda) com 15 anos de idade (floresta de pinus).

c. Cultura da seringueira com 10 anos de idade (seringueira).

d. Cultura de abacate com cinco anos de idade (abacate). 
e. Entrelinha da cultura de citrus com 5 anos de idade (citrus).

f. Cultura da cana-de-açúcar, soqueira de terceiro corte (cana-deaçúcar).

g. Cultura da banana com cinco anos de idade (banana).

h. Horta onde o cultivo de várias hortaliças tem sido feito durante muitos anos (hortaliças).

i. Cultura do milho em área cultivada com esta cultura há pelo menos seis anos (milho).

As amostras de solo foram retiradas de uma camada de $0-20 \mathrm{~cm}$ com o auxílio de um trado de $4,3 \mathrm{~cm}$ de diâmetro, previamente desinfestado superficialmente com solução de hipoclorito de sódio comercial 30\%. Cada amostra foi composta de quatro subamostras, as quais foram homogeneizadas e acondicionadas em sacos plásticos novos devidamente identificados. As amostras de solo foram imediatamente levadas ao laboratório e armazenadas a $4^{\circ} \mathrm{C}$ até o momento em que foi feito o isolamento dos actinomicetos.

\subsubsection{Isolamento dos actinomicetos}

Os isolamentos foram feitos por diluição em série e plaqueamento em meio seletivo. Para isso, uma subamostra de $10 \mathrm{~g}$ de solo foi suspensa em $90 \mathrm{~mL}$ de solução salina $(0,85 \% \mathrm{NaCl})$ esterilizada. Diluições em série $(10 \mathrm{x})$ até $10^{-6} \mathrm{~g}$ solo $\mathrm{mL}^{-1}$ foram preparadas em solução salina. Uma alíquota de $100 \mu \mathrm{L}$ de cada diluição foi transferida para meio glicerina-caseina-agar $(10,0 \mathrm{~g}$ glicerina; $0,3 \mathrm{~g}$ caseína hidrolisada; 2,0 $\mathrm{g} \mathrm{KNO}_{3} ; 2,0 \mathrm{~g} \mathrm{NaCl} ; 2,0$ g K ${ }_{2} \mathrm{HPO}_{4} ; 0,05$ g MgSO 
$\mathrm{g} \mathrm{CaCO}_{3} ; 0,01 \mathrm{~g} \mathrm{FeSO}_{4}$ e 18,0 g agar em $1 \mathrm{~L}$ de $\mathrm{H}_{2} \mathrm{O}$ destilada com pH 7,8 antes de autoclavado), em placas de petri. As placas foram incubadas a $25^{\circ} \mathrm{C}$ em câmara úmida até que as colônias puderam ser visualizadas (aproximadamente 1-3 semanas). As placas foram devidamente etiquetadas para que as colônias formadas sejam correlacionadas com a área onde o solo foi coletado.

Colônias isoladas, típicas de actinomicetos, foram transferidas para novas placas com meio glicerina-caseína-agar. Esse procedimento foi repetido até a obtenção de culturas puras. Os isolados foram armazenados em glicerol $50 \%$ a $-80^{\circ} \mathrm{C}$ e identificados com a letra relativa a cultura de origem segundo a tabela 2 seguidas do número da seqüência em que foram plaqueadas no processo de isolamento. Dos solos amostrados, foram isoladas e identificadas um total de 103 colônias visualmente diferentes.

Tabela 2. Número de isolados e letras de identificação do local de origem

\begin{tabular}{lcc}
\hline $\begin{array}{l}\text { Sistema de } \\
\text { produção/vegetação }\end{array}$ & $\mathbf{N}^{\mathbf{0}}$ de isolados & Letra de identificação \\
\hline Seringueira & 29 & SE \\
Abacate & 4 & $\mathrm{AB}$ \\
Banana & 8 & $\mathrm{BA}$ \\
Hortaliças & 4 & $\mathrm{HO}$ \\
Milho & 17 & $\mathrm{MI}$ \\
Mata-virgem & 7 & $\mathrm{MA}$ \\
Cana-de-açúcar & 9 & $\mathrm{CA}$ \\
Café & 8 & $\mathrm{CF}$ \\
Citrus & 6 & $\mathrm{CI}$ \\
Floresta de pinus & 11 & $\mathrm{FP}$ \\
Total & 103 & \\
\hline
\end{tabular}




\subsubsection{Screening primário - Teste de germinação}

Os testes de seleção primários, também conhecidos como screenings, visam a identificação de isolados de actinomicetos com capacidade para inibir a germinação de sementes e/ou o desenvolvimento de plântulas diante de uma grande diversidade de isolados.

Como plantas testes nos bioensaios de laboratório foram utilizados pepino (Cucumis sativus) e sorgo (Sorghum bicolor). Muito embora não sejam plantas daninhas, essas espécies são sensíveis aos herbicidas sintéticos e são de uso freqüente em bioensaios para detecção de resíduos de herbicidas sintéticos no solo. Além disso, as sementes dessas espécies possuem germinação rápida, uniforme e não apresentam dormência. O pepino e o sorgo representam as classes das dicotiledôneas e monocotiledôneas respectivamente, as quais apresentam comportamento diferenciado em resposta à aplicação de herbicidas sintéticos.

\subsubsection{Efeito do meio de cultura no desenvolvimento das plântulas de pepino e sorgo}

Os testes de germinação podem ser influenciados por vários fatores. Dentre eles destaca-se o potencial osmótico que pode variar segundo a concentração do meio de cultura. Assim foi feito um teste preliminar para verificar a influência da concentração do meio de cultura (potencial osmótico) na germinação e crescimento das plântulas.

Com o intuito de minimizar os efeitos do meio de cultura no desenvolvimento das plantas, podendo estes mascarar os efeitos esperados dos metabólitos microbiológicos, foi feita uma curva de regressão com cinco doses 
$(0 \%, 12,5 \%, 25 \%, 50 \%$ e $75 \%)$ do meio glicerina-caseína líquido $(10,0 \mathrm{~g}$ glicerina; 0,3 g caseína hidrolisada; 2,0 g KNO $\mathrm{g} \mathrm{MgSO}_{4} ; 0,02 \mathrm{~g} \mathrm{CaCO}_{3} ; 0,01 \mathrm{~g} \mathrm{FeSO}_{4}$ em $1 \mathrm{~L}$ de $\mathrm{H}_{2} \mathrm{O}$ destilada com pH 7,8 antes de autoclavado) em $\mathrm{H}_{2} \mathrm{O}$. O objetivo deste teste foi de identificar a concentração máxima para o teste de germinação que não afetaria o desenvolvimento das plântulas de maneira significativa.

Os resultados obtidos foram submetidos a uma análise de regressão, sendo então ajustadas curvas de regressão linear ou exponencial conforme a tendência dos resultados.

\subsubsection{Teste de germinação}

Os 103 microrganismos isolados foram cultivados em $10 \mathrm{~mL}$ de meio glicerina-caseína líquido (10,0 g glicerina; 0,3 g caseína hidrolisada; 2,0 $\mathrm{g} \mathrm{KNO}_{3}$; 2,0 g NaCl; 2,0 $\mathrm{g} \mathrm{K}_{2} \mathrm{HPO}_{4} ; 0,05 \mathrm{~g} \mathrm{MgSO}_{4} ; 0,02 \mathrm{~g} \mathrm{CaCO}_{3} ; 0,01 \mathrm{~g} \mathrm{FeSO}$ em $1 \mathrm{~L}$ de $\mathrm{H}_{2} \mathrm{O}$ destilada com $\mathrm{pH} 7,8$ antes de autoclavado) por sete dias sob agitação de 150 rpm a $25^{\circ} \mathrm{C}$ em erlenmeyer de $50 \mathrm{~mL}$. Após o sétimo dia estas culturas foram transferidas a erlenmeyers de $125 \mathrm{~mL}$ contendo $60 \mathrm{~mL}$ de meio glicerina-caseína líquido, permanecendo mais sete dias sob as mesmas condições.

Para o preparo da solução de metabólitos, extraiu-se o sobrenadante acelular dos meios de cultura centrifugando-os por 20 minutos a $15.000 \mathrm{G}$ e filtrando-os a vácuo com filtro $0,45 \mu \mathrm{m}$. Usou-se uma concentração de $33 \%$ de sobrenadante acelular em solução aquosa (a concentração de 33\% foi utilizada baseando-se nos resultados do efeito do meio de cultura no desenvolvimento das plântulas de pepino e sorgo), adicionada de alquil-fenol-poliglicoleter a $0,1 \%$ (v/v) 
(espalhante adesivo de nome comercial Extravon). Foi determinado o $\mathrm{pH}$ dos sobrenadantes acelulares.

No teste de germinação foi usado como substrato folhas de papel germiteste, normalmente utilizado em testes de germinação de sementes. Duas folhas foram dispostas em uma bandeja metálica e foram adicionadas aproximadamente $45 \mathrm{~mL}$ da solução de metabólitos uniformemente distribuída. Com um gabarito para distribuição eqüidistante das sementes foram dispostas 50 sementes, e estas cobertas com uma terceira folha, o conjunto foi enrolado e colocado dentro de um saco plástico a fim de isolar os tratamentos. Cada conjunto compreendeu uma espécie e um tratamento de metabólitos diferente. Os rolos foram incubados por 72 horas a $25^{\circ} \mathrm{C}$, em câmara úmida.

O total de isolados foi dividido para avaliação em três blocos no qual cada bloco apresentava dois tratamentos para comparação: um tratamento controle com uma concentração de $33 \%(\mathrm{v} / \mathrm{v})$ do meio de cultura não inoculado mais o espalhante adesivo $0,1 \%$, e um tratamento chamado de branco contendo somente $45 \mathrm{~mL}$ de água e espalhante adesivo $0,1 \%(\mathrm{v} / \mathrm{v})$.

A avaliação do efeito dos microrganismos na germinação e no desenvolvimento das plântulas foi feita visualmente e marcados com “_“ para nenhum efeito até “+++" para efeito acentuado comprometendo a germinação e/ou o desenvolvimento das plantas.

\subsubsection{Screening secundário - Câmara-de-crescimento}

Para os screenings em pós e pré-emergência em condições de câmarade-crescimento foram cultivadas plantas de pepino e de sorgo em vasos de 500 
$\mathrm{cm}^{3}$ contendo solo proveniente de uma área de solo franco-argiloso com $38 \%$ de argila, $19 \%$ de silte e $43 \%$ de areia, pH 5,3 e $37 \mathrm{~g} / \mathrm{dm}^{3}$ de matéria orgânica. Como no screening primário, no screening secundário foram testados todos os 103 microrganismos isolados.

Para obtenção dos sobrenadantes livres de células das culturas de microrganismos selecionados, foi utilizado o mesmo procedimento descrito anteriormente no teste de germinação do screening primário. Os sobrenadantes foram então diluídos em água destilada esterilizada nas concentrações de 1:0, 1:1 e 1:3 (vol. sobrenadante: vol. água). Para a aplicação foi adicionado um surfactante não iônico (nome comercial Agral) a $0,1 \%(\mathrm{v} / \mathrm{v})$. As soluções foram pulverizadas em câmara de aplicação de herbicidas com velocidade de aplicação constante calibrada para uma vazão de $150 \mathrm{~L} \mathrm{ha}^{-1}$, os bicos foram do tipo leque $8003 \mathrm{com}$ pressão de $2 \mathrm{kgf} \mathrm{cm}^{-2}$ e $50 \mathrm{~cm}$ de altura do bico em relação a plataforma de aplicação. Os tratamentos controle foram compostos do meio de cultura não inoculado mais o espalhante adesivo a $0,1 \%(\mathrm{v} / \mathrm{v})$. Também foi adotado um tratamento chamado de branco contendo somente $45 \mathrm{~mL}$ de água e espalhante adesivo a $0,1 \%$.

A aplicação em pós-emergência ocorreu 10 dias após a semeadura das espécies tratadas. Neste momento, o pepino apresentava duas a três folhas verdadeiras completamente desenvolvidas, e o sorgo uma a duas folhas verdadeiras completamente estendidas. Foi feito um desbaste de modo a permanecerem apenas quatro plantas por vaso. Os tratamentos em pré-emergência foram semeados no dia da aplicação dos tratamentos em pós-emergência, sendo assim, as pulverizações com os extratos foram simultâneas nos tratamentos em pré e pós-emergência. $\mathrm{O}$ tratamento em pré-emergência foi desbastado aleatoriamente 10 dias após a semeadura, de modo a permanecerem quatro plantas por vaso. 
A câmara-de-crescimento, onde foram conduzidos os testes de seleção secundários, apresenta um sistema de iluminação composto por lâmpadas do tipo fluorescente e incandescente controlado por um "timer", simulando um dia com 12 horas de luminosidade. A irrigação foi feita de forma manual. A câmara-decrescimento também possui um sistema automático de controle de temperatura e umidade relativa, os quais mantiveram os parâmetros de $28^{\circ} \mathrm{C}$ e $80 \%$ U.R. com as luzes acesas e de $24^{\circ} \mathrm{C}$ e $60 \%$ U.R. com as luzes apagadas.

Os sintomas de fitotoxicidade foram avaliados aos 40 dias após a germinação através de inspeção visual e atribuição de notas, de acordo com os sintomas, sendo marcados com “_“ para nenhum efeito até “+++” para efeito acentuado comprometendo a germinação e/ou o desenvolvimento das plantas.

\subsection{Teste do sobrenadante das culturas selecionadas nos screenings em condições de casa-de-vegetação.}

O objetivo do teste de seleção secundário foi avaliar estatisticamente o efeito dos sobrenadantes livres de células das culturas dos microrganismos que foram selecionados nos screenings (testes de seleção primários) no crescimento de espécies de plantas teste e de plantas daninhas.

Para este teste foram selecionados apenas os isolados identificados nos testes de seleção primários com “+++".

Inicialmente os isolados foram cultivados em meio Glicerina-caseina líquido, em frascos erlenmeyer por 14 dias, a $25^{\circ} \mathrm{C}$ e sob agitação constante de $150 \mathrm{rpm}$ (mesmo procedimento descrito nos screenings). Tanto para os testes em 
pós-emergência como em pré-emergência das plantas daninhas foi utilizado o mesmo procedimento.

Em condições de casa-de-vegetação foram cultivadas plantas de pepino (Cucumis sativus), sorgo (Sorghum bicolor), picão-preto (Bidens pilosa) e capimcolchão (Digitaria ciliaris) em vasos com capacidade de $500 \mathrm{~cm}^{3}$, contendo solo proveniente de uma área de solo franco argiloso com 38\% de argila, 19\% de silte e $43 \%$ de areia, pH 5,3 e $37 \mathrm{~g} / \mathrm{dm}^{3}$ de matéria orgânica. As espécies de pepino e sorgo foram escolhidas pelas já referidas características de sensibilidade aos herbicidas sintéticos e representam as classes das dicotiledôneas e monocotiledôneas respectivamente. As espécies de picão-preto e capim-colchão foram escolhidas por serem plantas daninhas de importância na agricultura brasileira, representando as classes das dicotiledôneas e monocotiledôneas respectivamente.

Para obtenção dos sobrenadantes livres de células das culturas de microrganismos selecionados, foi utilizado o mesmo procedimento descrito anteriormente. Os sobrenadantes livres de células das culturas de microrganismos selecionados nos screenings foram diluídos em água destilada esterilizada nas concentrações de 1:0, 1:1 e 1:3 (vol. sobrenadante: vol. água). Para a aplicação foi adicionado um surfactante não iônico (nome comercial Agral) a 0,1\% (v/v). As soluções foram pulverizadas em câmara de aplicação de herbicidas com velocidade de aplicação constante calibrada para uma vazão de $150 \mathrm{~L} \mathrm{ha}^{-1}$, os bicos foram do tipo leque $8003 \mathrm{com}$ pressão de $2 \mathrm{kgf} \mathrm{cm}^{-2}$ e $50 \mathrm{~cm}$ de altura do bico em relação à plataforma de aplicação.

A aplicação em pós-emergência ocorreu 10 dias após a semeadura das espécies tratadas. Neste momento o pepino e o picão-preto apresentavam duas a 
três folhas verdadeiras completamente desenvolvidas, o sorgo e o capim-colchão uma a duas folhas verdadeiras completamente estendidas. Foi feito um desbaste de modo a permanecerem apenas quatro plantas por vaso. Os tratamentos em préemergência foram semeados no dia da aplicação dos tratamentos em pósemergência, sendo assim, as pulverizações com os extratos foram simultâneas nos tratamentos em pré e pós-emergência. O tratamento em pré-emergência foi desbastado aleatoriamente 10 dias após a semeadura, de modo a permanecerem quatro plantas por vaso.

O delineamento experimental foi blocos ao acaso no esquema de parcelas subdivididas com oito tratamentos, três repetições e três doses relativas aos sub-tratamentos, onde a unidade experimental foi composta por um vaso com quatro plantas. Os tratamentos controle foram compostos do meio de cultura não inoculado mais o espalhante adesivo na concentração de $0,1 \%(\mathrm{v} / \mathrm{v})$. Também foi adotado um tratamento chamado de branco contendo somente $45 \mathrm{~mL}$ de água e espalhante adesivo na concentração de $0,1 \%$.

A casa-de-vegetação, onde foram conduzidos os testes de seleção secundários, apresenta um sistema de irrigação composto por microaspersores controlados por um "timer", irrigando aproximadamente $5 \mathrm{~mm}$ quando é acionado, sendo acionado cinco vezes por dia. A casa de vegetação possui um sistema automático de controle de temperatura e umidade relativa, através de ventiladores.

Os sintomas de fitotoxicidade foram avaliados aos 40 dias após a germinação através de mensuração do peso da matéria vegetal verde (PF) e da área folhar $(\mathrm{AF})$. 
Os dados foram submetidos ao teste $\mathrm{F}$ de análise de variância e utilizou-se o teste de Tukey ao nível de 5\% de probabilidade para comparar as médias, isto foi feito por meio do programa de computador SAS (Statistical Analysis Systems). 


\section{RESULTADOS E DISCUSSÃO}

Destaca-se que a metodologia utilizada nesta pesquisa simplifica o procedimento adotado sem perder informações importantes que são geradas em procedimentos mais sofisticados, descritos na literatura por Stonard \& MillerWideman (1995), como os ensaios com plantas inteiras dentre outros métodos. Ressalta-se também que o procedimento utilizado nesta pesquisa detecta fitotoxinas de alto potencial fitoinibitório, o que é o objetivo da busca de novos herbicidas para a agricultura. Fitotoxinas de baixo potencial herbicida teriam pequenas chances de tornarem-se futuros herbicidas de uso extensivo na agricultura. Para que um novo herbicida tenha chance de sucesso na agricultura atual ele deve apresentar alta eficiência agronômica dentre outras características.

Escolheu-se a Ordem Actinomycetales como ponto de partida para a procura de produtores de fitotoxina pela conhecida diversidade química dos compostos produzidos pelos membros deste grupo (Umezawa, 1967). Como o objetivo da pesquisa era isolar microrganismos com potencial de produção de fitotoxinas, foram feitos os isolamentos direcionados a este grupo de procariotos.

Os actinomicetos são microrganismos gram-positivos pertencentes à Ordem Actinomicetales, com crescimento filamentoso assemelhando-se a hifas fúngicas com diâmetro entre 0,5 e 2,0 $\mu \mathrm{m}$ (Gottlieb, 1973; Williams \& Wellington, 1982). Em meio de cultura sólido, formam-se filamentos ramificados 
firmemente aderidos ao agar que crescem como micélio fúngico, em sua extremidade formam-se esporos assexuados, dando à colônia aparência característica de algodão, veludo ou pó (Pereira, 1995). Desta forma, seguindo esta caracterização, foi possível direcionar o isolamento dos microrganismos somente a este grupo.

\subsection{Potencialidade dos diferentes sistemas de produção/vegetação}

Na tabela 3 pode ser observado que do total de 103 isolados, 18,5\% apresentaram algum efeito fitoinibitório no experimento. $\mathrm{Na}$ pesquisa desenvolvida por Misha et al. (1988) foram estudados 796 isolados de actinomicetos, dentre estes 66 apresentaram efeito fitoinibitório, ou seja 8,29\%. De Frank \& Putnam (1985) obtiveram a inibição de germinação por oito isolados de actinomicetos à partir de 120 isolados testados, reduzindo em mais de $60 \%$ a germinação de capim-arroz e pepino, provando assim que o potencial alelopático dos actinomicetos isolados na presente pesquisa é maior que os relatados na literatura, podendo estes terem uma maior diversidade de produção de metabólitos fitotóxicos.

Dentre os sistemas de produção e/ou vegetação testados, a cultura da cana-de-açúcar foi a que contribuiu com a maior porcentagem de isolados com potencial fitoinibitório (tabela 3). É importante destacar que não foi possível isolar o mesmo número de colônias de actinomicetos de cada um dos sistemas de produção e/ou vegetação, isto permitiria melhores conclusões sobre os sistemas de maior potencial como fonte de actinomicetos produtores de compostos fitotóxicos. $\mathrm{O}$ isolamento do número de colônias de actinomicetos de forma desigual foi decorrente do fato da possibilidade de isolamento de colônias puras durante o processo de diluição. 
Tabela 3. Número total de isolados e o respectivo número e porcentagem de isolados com algum efeito fitoinibitório sobre plantas de pepino e sorgo nos testes de germinação e/ou câmara-de-crescimento (pré e/ou pósemergência)

\begin{tabular}{lccc}
\hline $\begin{array}{l}\text { Sistema de } \\
\text { Produção/ } \\
\text { Vegetação }\end{array}$ & $\mathrm{N}^{\mathrm{o}}$ de isolados (A) & $\begin{array}{l}\mathrm{N}^{\mathrm{o}} \text { de isolados com algum } \\
\text { efeito fitotóxico em pré e/ou } \\
\text { pós-emergência (B) }\end{array}$ & $\begin{array}{l}(\mathrm{B} / \mathrm{A}) \times 100 \\
(\%)\end{array}$ \\
\hline $\mathrm{SE}$ & 29 & 3 & 10,3 \\
$\mathrm{AB}$ & 4 & 0 & 0,0 \\
$\mathrm{BA}$ & 8 & 1 & 12,5 \\
$\mathrm{HO}$ & 4 & 1 & 25,0 \\
MI & 17 & 4 & 23,5 \\
MA & 7 & 2 & 28,6 \\
$\mathrm{CA}$ & 9 & 5 & 55,6 \\
$\mathrm{CF}$ & 8 & 0 & 0,0 \\
$\mathrm{CI}$ & 6 & 0 & 0,0 \\
FP & 11 & 3 & 27,3 \\
Total & 103 & 19 & 18,5 \\
\hline
\end{tabular}

\subsection{Efeito do meio de cultura no desenvolvimento das plântulas de pepino e sorgo}

O meio de cultura afetou sensivelmente o teste de germinação para as características de comprimento de radícula e de caulículo do pepino e afetou consideravelmente o crescimento de radícula do sorgo, não interferindo no crescimento de caulículo desta planta (figura 3).

Com exceção da radícula do sorgo, observou-se que os efeitos de inibição começaram a serem pronunciados em diluições de 50\% do meio de cultura. Também foi observado que em um nível de 33\% de concentração do meio de cultura as plantas não foram afetadas significativamente pelo meio de cultura, 
determinando-se uma concentração ideal para o teste de germinação com os metabólitos (figura 3). Desta forma este resultado serviu de base para que os ensaios de screening primário (teste de germinação) em laboratório fossem feitos na concentração de $33 \%$ do concentrado acelular obtido do meio de cultura. Ressalta-se portanto que esta pode ser uma limitação do método empregado, especialmente para fitotoxinas que possivelmente são produzidas em menor escala pelos microrganismos.

Uma discussão completa sobre as diversas metodologias de isolamento e seleção de actinomicetos com efeitos fitoinibitórios está descrita em Stonard \& Miller-Wideman (1995), onde também é destacada a preocupação com a concentração do meio de cultura e seus efeitos indiretos nos resultados. Concentrações de até $50 \%$ são recomendadas na literatura, porém na presente pesquisa foi adotada uma concentração mais conservadora, ou seja 33\%, mesmo correndo riscos de resultados menos expressivos de fitoinibição. 

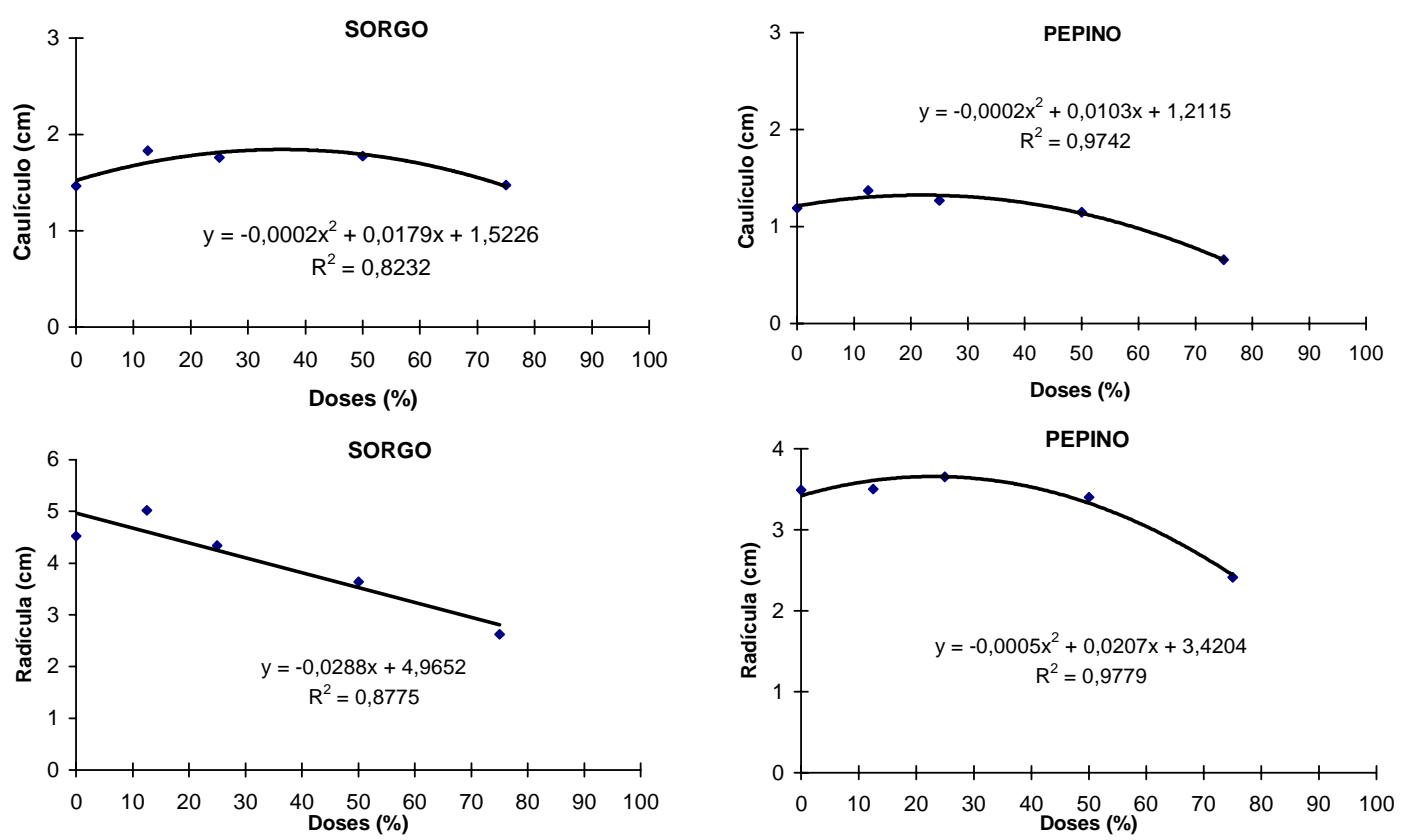

Figura 3 - Curvas de regressão do efeito das doses do meio de cultura no desenvolvimento do caulículo e da radícula do sorgo e do pepino

\subsection{Screenings de seleção primário e secundário}

Nas fotos da figura 4 observa-se o efeito inibitório do composto produzido pelo actinomiceto extraído do sistema de produção $\mathrm{MI}$, isolado número 11, através da inibição do crescimento da radícula, sem no entanto, inibir o crescimento do caulículo. Ainda observa-se nas radículas uma coloração ruborizada atípica. Os mesmos resultados foram obtidos na figura 5, com o isolado MA1. Neste caso a inibição do crescimento inicial foi tanto do caulículo como da radícula, mostrando potencial de existência de uma fitotoxina de préemergência. 
Segundo Stonard \& Miller-Wideman (1995), dentre as características desejáveis de uma substância natural fitotóxica proveniente de microrganismos é essencial que seja biodegradável, tenha mecanismo de ação específico a processos fisiológicos e/ou metabólicos das plantas e atue seletivamente. Através dos resultados observados nas figuras 4 e 5 fica evidente que o composto fitotóxico existente nos isolados MI11 e MA1 é seletivo para gramíneas e dicotiledôneas respectivamente. Pela sintomatologia observada nas plantas é possível que o mecanismo de ação do composto fitotóxico presente nos isolados esteja ligado ao crescimento inicial das regiões meristemáticas, relacionado com a divisão celular.

Estes actinomicetos possivelmente produzem uma substância ou combinação de substâncias que teriam potencial de isolamento e futuro desenvolvimento como herbicida inibidor do crescimento inicial das plantas. Atualmente na agricultura são aplicados herbicidas sintéticos que apresentam este tipo de atividade, como é o caso da trifluralina e dos herbicidas do grupo das acetanilidas (alachlor e metalachlor, por exemplo) que apresentam extensiva utilização na agricultura. 

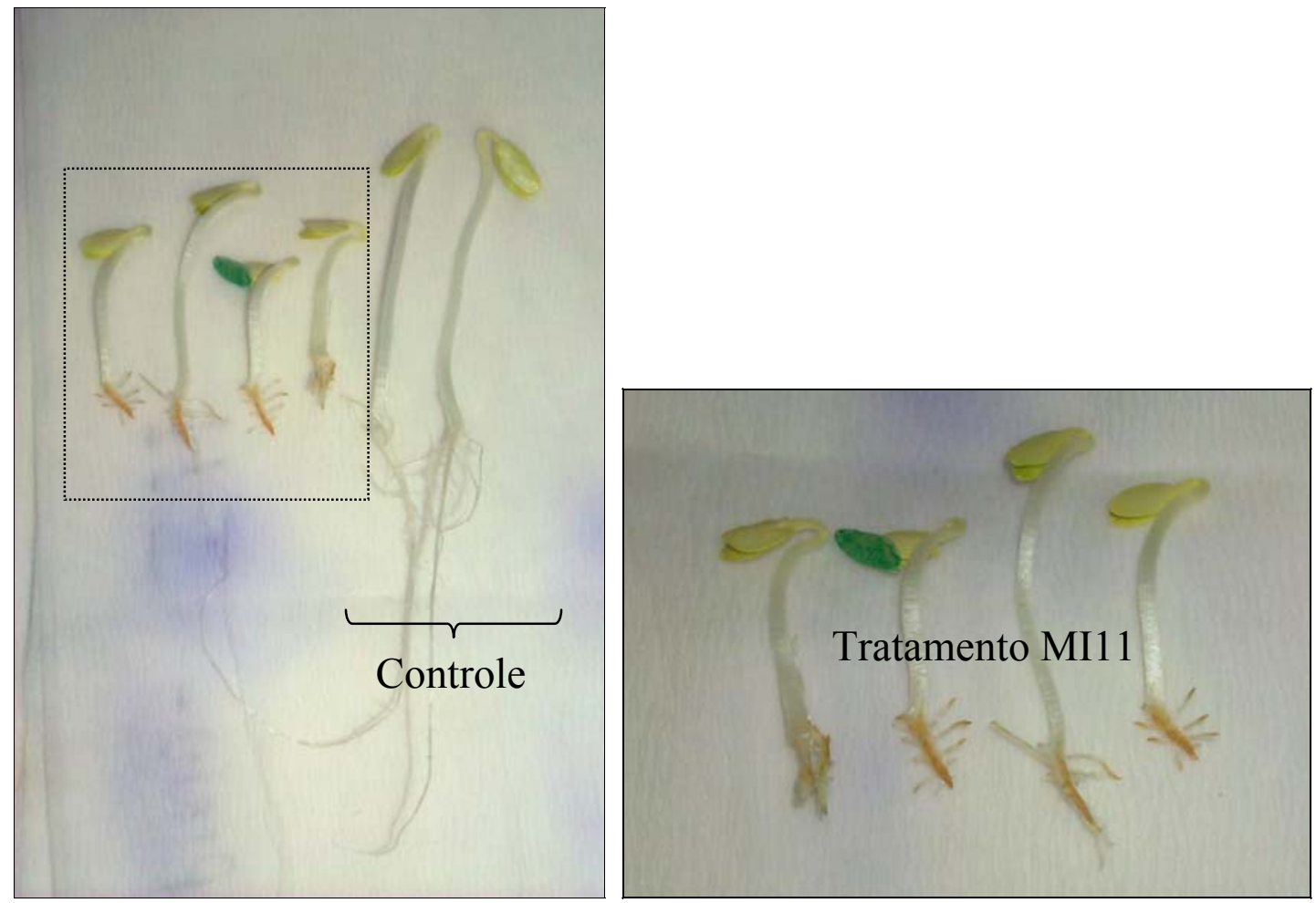

Figura 4 - Efeito inibidor sobre a radícula mediante o tratamento proveniente dos exudatos do isolado MI11 em plantas de pepino
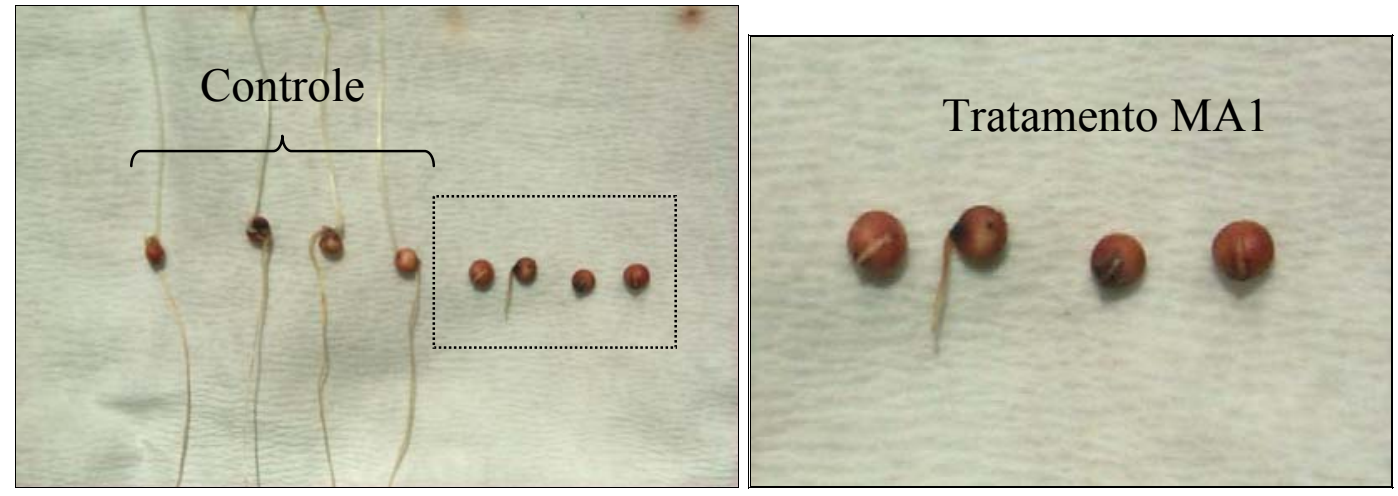

Figura 5 - Efeito inibidor da germinação mediante o tratamento proveniente dos exudatos do isolado MA1 em plantas de sorgo 
Na tabela 4 são apresentados os resultados do teste de germinação em laboratório e dos testes em câmara-de-crescimento, sendo que neste último os metabólitos dos isolados foram aplicados em condições de pré e pós-emergência. Observa-se que não houve repetitividade de resultados dos testes de germinação em laboratório e dos testes em câmara-de-crescimento, sendo que melhores resultados foram obtidos em pré-emergência comparando-se as condições de pósemergência. Uma das possíveis explicações para os resultados de pós-emergência serem abaixo do esperado, pode estar relacionada com o processo de absorção da fitotoxina na folha. Embora tenha sido adicionado espalhante adesivo à calda de pulverização, para que a fitotoxina atinja o sítio de ação é necessário que seja absorvida através da cutícula das folhas (Zimdahl, 1991) e não apresente assim uma barreira à ação deste produto.

Quando um produto químico com atividade herbicida é aplicado ao solo (pré-emergência) sua atividade no controle de plantas daninhas depende dos processos de retenção (adsorção e absorção), de transformação (degradação química ou microbiológica), de transporte (deriva, volatilização, lixiviação e fotodecomposição) e por interações desses processos (Oliveira, 2001). Portanto, a atividade das fitotoxinas nos tratamentos desta pesquisa deve ter sofrido a influência desses processos em maior ou menor grau, dependendo da natureza química da fitotoxina, a qual é desconhecida.

Para que um herbicida aplicado às folhas das plantas atue de forma adequada é necessário que a molécula inicialmente seja retida pela folha. Neste momento a natureza da calda de aplicação e a estrutura química da molécula desempenham um papel fundamental na eficácia do produto (Christoffoleti \& Dourado Neto, 2001). Em seguida o herbicida deve atravessar a cutícula, a qual tem natureza hidrofílica e lipofílica, portanto o caráter aquoso ou lipoidal da 
molécula é fundamental nesta passagem pela cutícula. Após esta etapa o herbicida ainda deve penetrar no simplasto (herbicida de translocação simplástica) ou através do apoplasto ser translocado até o sítio de ação. Desta forma, na presente pesquisa todos os fatores que afetam a eficácia de uma fitotoxina em pósemergência podem ter atuado e conseqüentemente dificultando a obtenção de resultados mais positivos dos actinomicetos com potencial de produção de fitotoxinas.

Tabela 4. Efeito fitoinibitório dos metabólitos de microrganismos sobre as plantas de pepino e sorgo nos testes de seleção primários e as medidas de $\mathrm{pH}$ das soluções que continham estes metabólitos

\begin{tabular}{|c|c|c|c|c|c|c|c|}
\hline \multirow{3}{*}{ Isolados } & \multirow{2}{*}{\multicolumn{2}{|c|}{ Teste de Germinação }} & \multicolumn{4}{|c|}{ Bioensaio - câmara-de-crescimento } & \multirow{3}{*}{$\mathbf{p H}$} \\
\hline & & & \multicolumn{2}{|c|}{ Pré-emergência } & \multicolumn{2}{|c|}{ Pós-emergência } & \\
\hline & Pepino & Sorgo & Pepino & Sorgo & Pepino & Sorgo & \\
\hline MI 11 & +++ & - & - & - & + & - & 7,2 \\
\hline MA 1 & + & +++ & - & - & - & - & 7,9 \\
\hline CA 1 & + & - & - & - & - & - & 7,8 \\
\hline FP 1 & + & + & - & - & - & - & 9,0 \\
\hline CA 4 & - & + & - & - & - & - & 7,7 \\
\hline CA 5 & - & + & - & - & - & - & 6,8 \\
\hline CA 9 & ++ & - & - & - & + & - & 9,0 \\
\hline MI 9 & - & - & - & - & ++ & - & 9,1 \\
\hline SE 5 & - & - & - & - & ++ & - & 9,3 \\
\hline CA 6 & - & - & - & - & + & - & 9,3 \\
\hline SE 14 & - & - & - & - & + & - & 8,3 \\
\hline SE 12 & - & - & + & - & - & - & 8,3 \\
\hline FP 3 & - & - & + & - & - & - & 7,6 \\
\hline HO 4 & - & - & +++ & - & - & - & 7,7 \\
\hline BA 5 & - & - & ++ & - & - & - & 7,7 \\
\hline FP 11 & - & - & ++ & ++ & - & - & 8,6 \\
\hline MI 12 & - & - & - & +++ & - & - & 5,5 \\
\hline MI 15 & - & - & - & +++ & - & - & 6,6 \\
\hline MA 5 & - & - & - & +++ & - & - & 8,5 \\
\hline \multicolumn{8}{|c|}{ nenhum efeito } \\
\hline \multicolumn{8}{|c|}{+ pouco efeito com posterior recuperação das plantas } \\
\hline \multicolumn{8}{|c|}{$++\quad$ efeito significativo } \\
\hline
\end{tabular}




\subsection{Teste do sobrenadante das culturas selecionadas nos screenings em condições de casa-de-vegetação.}

Os testes em casa-de-vegetação foram feitos apenas para os isolados que receberam notas "+++" no teste de germinação ou no bioensaio em câmarade-crescimento. Desta forma, observando a tabela 4 verifica-se que os isolados MI1, MA1, HO4, MI12, MI15 e MA5 foram os que apresentaram nota “+++" e portanto elegíveis para este teste, sendo os demais descartados. É evidente que eliminando-se do teste em casa-de-vegetação os isolados com notas "++" e "+" é possível estar descartando bons isolados, cuja fitotoxina encontra-se em baixa concentração, porém por questões de viabilização da pesquisa em um experimento de tamanho adequado optou-se por concentrar os esforços nos isolados mais promissores.

A análise estatística das variáveis peso da matéria verde e área folhar, nas aplicações em pós e em pré-emergência dos sobrenadantes acelulares, estão apresentados nas tabelas 5 e 6 respectivamente. As variáveis e interações, cujo teste $\mathrm{F}$ foi significativo ( $\mathrm{P} \leq 0,01 ; 0,05$ e 0,10$)$, foram então submetidas ao teste de comparação de médias de Tukey a 5\% de probabilidade.

Observa-se pelas tabelas 5 e 6 que na maioria das culturas e plantas daninhas estudadas, tanto em pós quanto em pré-emergência não apresentaram efeitos significativos dos sobrenadantes acelulares e de suas doses, bem como das interações entre tratamentos e doses. Estes resultados eram esperados, pois os possíveis efeitos fitoinibitórios dos aleloquímicos são dependentes da absorção folhar quando aplicados em pós-emergência ou absorção radicular quando aplicados em pré-emergência, sendo que estas observações dependem basicamente de uma formulação adequada da calda de pulverização. Na presente pesquisa não 
foi feita nenhuma formulação para aplicação dos possíveis aleloquímicos, exceto a adição de um espalhante adesivo. A seguir são feitos alguns comentários sobre os tratamentos, doses e interações significativas estatisticamente apresentados nas tabelas 5 e 6.

Tabela 5. Quadro de análises estatísticas, com os valores dos quadrados médios (QM), para as variáveis PV (peso da matéria verde) e AF (área folhar) em aplicação de pós-emergência

\begin{tabular}{|c|c|c|c|c|c|c|c|c|c|}
\hline \multirow{3}{*}{ C.V. } & \multirow{3}{*}{ G.L. } & \multicolumn{8}{|c|}{ Q.M. } \\
\hline & & \multicolumn{2}{|c|}{ Pepino } & \multicolumn{2}{|c|}{ Sorgo } & \multicolumn{2}{|c|}{ Picão-preto } & \multicolumn{2}{|c|}{ Capim-colchão } \\
\hline & & PV & $\mathrm{AF}$ & PV & $\mathrm{AF}$ & PV & $\mathrm{AF}$ & PV & $\mathrm{AF}$ \\
\hline Bloco & 2 & 250,04 & 30032,93 & 980,43 & 628647,04 & 183,69 & 142330,26 & 60,11 & 50284,01 \\
\hline Trat. & 7 & $13,21^{*}$ & 4734,11 & $7,17^{+}$ & 3116,16 & 2,54 & 1499,03 & $1,96 * *$ & $1051,68^{+}$ \\
\hline $\begin{array}{l}\text { Res. (a) } \\
\text { (Parcelas) }\end{array}$ & $\begin{array}{l}14 \\
(23)\end{array}$ & 12,97 & 6687,41 & 5,04 & 2380,58 & 5,60 & 3609,66 & 2,29 & 904,28 \\
\hline Doses & 2 & 2,00 & 4142,51 & 4,60 & 2062,04 & $9,19 *$ & $6190,18^{*}$ & 0,18 & 296,42 \\
\hline Tr. x Dos. & 14 & 6,91 & 3048,66 & 3,22 & 1999,87 & 3,14 & 1692,15 & $1,54 * *$ & 773,66 \\
\hline Res. (b) & 32 & 4,96 & 2508,39 & 3,24 & 1892,64 & 2,68 & 1718,76 & 0,56 & 466,71 \\
\hline Total & 71 & & & & & & & & \\
\hline
\end{tabular}

** significativo ao nível de $1 \%$ de probabilidade no teste $\mathrm{F}$

* significativo ao nível de $5 \%$ de probabilidade no teste $\mathrm{F}$

${ }^{+}$significativo ao nível de $10 \%$ de probabilidade no teste $\mathrm{F}$

Doses $=$ concentração do sobrenadante acelular dos isolados 
Tabela 6. Quadro de análises estatísticas, com os valores dos quadrados médios (QM), para as variáveis PV (peso da matéria verde) e AF (área folhar) em aplicação de pré-emergência

\begin{tabular}{|c|c|c|c|c|c|c|c|c|c|}
\hline \multirow{3}{*}{ C.V. } & \multirow{3}{*}{ G.L. } & \multicolumn{8}{|c|}{ Q.M. } \\
\hline & & \multicolumn{2}{|c|}{ Pepino } & \multicolumn{2}{|c|}{ Sorgo } & \multicolumn{2}{|c|}{ Picão-preto } & \multicolumn{2}{|c|}{ Capim-colchão } \\
\hline & & $\mathrm{PV}$ & $\mathrm{AF}$ & $\mathrm{PV}$ & $\mathrm{AF}$ & PV & $\mathrm{AF}$ & PV & $\mathrm{AF}$ \\
\hline Bloco & 2 & 114,29 & 98,46 & 2943,25 & 84,97 & 1543,72 & 13,77 & 8314,35 & 54,15 \\
\hline Trat. & 7 & $107,70^{+}$ & $16,63 * *$ & 182,29 & 4,83 & $240,12^{+}$ & 1,40 & 195,16 & $4,67^{*}$ \\
\hline $\begin{array}{l}\text { Res. (a) } \\
\text { (Parcelas) }\end{array}$ & $\begin{array}{l}14 \\
(23)\end{array}$ & 19,16 & 14,76 & 138,81 & 7,58 & 97,50 & 2,63 & 273,97 & 7,30 \\
\hline Doses & 2 & 8,20 & 9,16 & 457,90 & 1,11 & 26,06 & 0,10 & 484,01 & 0,54 \\
\hline Tr. x Dos. & 14 & 43,22 & 3,41 & 140,44 & $6,07 *$ & 156,79 & 1,11 & 213,54 & 1,85 \\
\hline Res. (b) & 32 & 49,00 & 4,42 & 189,07 & 2,61 & 116,78 & 1,02 & 279,72 & 1,59 \\
\hline Total & 71 & & & & & & & & \\
\hline
\end{tabular}

** significativo ao nível de $1 \%$ de probabilidade no teste $\mathrm{F}$

* significativo ao nível de $5 \%$ de probabilidade no teste $\mathrm{F}$

+ significativo ao nível de $10 \%$ de probabilidade no teste $\mathrm{F}$

Doses $=$ concentração do sobrenadante acelular dos isolados

$\mathrm{Na}$ tabela 7 encontram-se as médias do peso da matéria verde do pepino e do sorgo independente da dose dos compostos acelulares. Pode ser observado que o tratamento 4 (MI11) diferiu estatisticamente do tratamento 3 (MI15) para o pepino, sendo os demais estatisticamente semelhantes entre si. Este efeito de inibição do tratamento 4 (MI11) em plantas de pepino foi também observado no teste de germinação do screening primário (figura 4 e tabela 4). Já para o sorgo, observa-se que o tratamento 6 (MA5) diferiu estatisticamente do tratamento 5 (HO4). O efeito inibidor do tratamento 6 (MA5) também pode ser observado no experimento em pré-emergência, com a redução do peso da matéria verde do picão-preto (tabela 12) e inibição da área folhar do capim-colchão (tabela 13), e no screening de seleção secundário em pré-emergência nas plantas de sorgo (tabela 4). Estes resultados indicam que os isolados de microrganismos tiveram 
um efeito pouco pronunciado sobre as plantas de pepino e sorgo, porém estes efeitos devem ser mais bem estudados, pois não se conhece a concentração da(s) fitotoxina(s) nos isolados. Desta forma, destaca-se o potencial como herbicida pós-emergente para plantas do tipo folha larga (dicotiledôneas) através de fitotoxinas contidas no isolado do tratamento 4 (MI11), e potencial como herbicida pré-emergente para plantas do tipo gramíneas (monocotiledôneas) através de fitotoxina(s) contida(s) no isolado do tratamento 6 (MA5).

Tabela 7. Peso da matéria verde das plantas de pepino e de sorgo em função dos tratamentos com os isolados independentemente da dose utilizada no experimento em pós-emergência

\begin{tabular}{lllll}
\hline \multirow{2}{*}{ Tratamentos } & \multicolumn{4}{c}{$\begin{array}{c}\text { Peso da matéria verde (PV) } \\
\text { Pepino }\end{array}$} \\
\hline 1. testemunha & 13,93 & $\mathrm{AB}$ & 5,97 & $\mathrm{AB}$ \\
2. branco & 15,39 & $\mathrm{AB}$ & 5,00 & $\mathrm{AB}$ \\
3. MI15 & 16,66 & $\mathrm{~A}$ & 5,79 & $\mathrm{AB}$ \\
4. MI11 & 12,70 & $\mathrm{~B}$ & 4,68 & $\mathrm{AB}$ \\
5. HO4 & 14,12 & $\mathrm{AB}$ & 7,13 & $\mathrm{~A}$ \\
6. MA5 & 13,71 & $\mathrm{AB}$ & 4,28 & $\mathrm{~B}$ \\
7. MA1 & 13,62 & $\mathrm{AB}$ & 5,32 & $\mathrm{AB}$ \\
8. MI12 & 14,21 & $\mathrm{AB}$ & 5,90 & $\mathrm{AB}$ \\
\hline Obs: médias acompanhadas de mesma letra na coluna são estatisticamente semelhantes entre si segundo o
\end{tabular}

Para a planta daninha picão-preto em condições de pós-emergência foi observada diferença significativa a $5 \%$ de probabilidade no teste $\mathrm{F}$ nas doses empregadas (tabela 5), tanto no peso da matéria verde quanto na área folhar. Fica evidente na tabela 8 que as doses mais concentradas dos compostos inibiram com maior intensidade tanto o peso da matéria verde quanto a área folhar da planta daninha apesar de o teste de Tukey a 5\% de significância não ter indicado esta 
diferença. Através destes resultados é possível concluir que existe efeito da(s) fitotoxina(s), porém este efeito é dependente da concentração. Portanto, novos estudos devem ser conduzidos com o objetivo de melhor estudar a concentração e posterior isolamento da(s) fitotoxina(s) com potencial herbicida.

Tabela 8. Peso da matéria verde (PV) e área folhar (AF) das plantas de picãopreto em função dos tratamentos e das doses utilizados no experimento de pós-emergência

\begin{tabular}{lcc}
\hline Doses & PV & AF \\
\hline $1: 0$ & 4,38 & 118,21 \\
$1: 1$ & 5,37 & 144,50 \\
$1: 3$ & 5,51 & 147,33 \\
\hline Apesar do teste F ser significativo, não foram encontradas diferenças entre as médias pelo teste de Tukey \\
ao nível de 5\% de probabilidade
\end{tabular}

Na tabela 9 pode ser observado que a área folhar do capim-colchão foi significativamente afetada pelos isolados aplicados em pós-emergência independente da interação com a dose. Observa-se que o tratamento 3 (MI15) afetou de forma significativa a área folhar quando comparado com a testemunha, estes também foram semelhantes aos demais tratamentos inclusive a testemunha branco. O tratamento 3 (MI15) teve um comportamento semelhante no screening secundário em pré-emergência das plantas de sorgo (tabela 4), que representam como o capim-colchão a classe das monocotiledôneas.

Apesar da diferença na interação entre tratamento e doses ser significativa, não há uma evidência clara desta interação na tabela 9. Comparandose nas linhas, não foi observada nenhuma diferença significativa entre as doses. Comparando-se nas colunas, observa-se que nas concentrações 1:0 e 1:3 não 
houve efeito significativo de nenhum dos tratamentos, porém para a concentração 1:1, o tratamento MI15 reduziu significativamente a matéria verde em relação ao tratamento HO4. O capim-colchão é uma planta daninha de grande importância para a agricultura brasileira e mundial, portanto, a descoberta de novos produtos com ação fitoinibitória é fundamental para auxiliar o manejo desta espécie.

Tabela 9. Peso da matéria verde (PV) e área folhar (AF) das plantas de capimcolchão em função dos tratamentos e das doses utilizados no experimento de pós-emergência

\begin{tabular}{lllllllll}
\hline Tratamentos & \multicolumn{4}{c}{ Peso da matéria verde (PV) } & \multicolumn{2}{c}{$\begin{array}{c}\text { Área folhar } \\
\text { (AF) }\end{array}$} \\
\hline 1. testemunha & 4,73 & $\mathrm{ab}$ & 4,73 & $\mathrm{ab}$ & 4,73 & $\mathrm{ab}$ & 119,67 & $\mathrm{~A}$ \\
2. branco & 4,43 & $\mathrm{ab}$ & 3,47 & $\mathrm{ab}$ & 4,23 & $\mathrm{ab}$ & 103,56 & $\mathrm{AB}$ \\
3. MI15 & 3,20 & $\mathrm{~b}$ & 2,93 & $\mathrm{~b}$ & 4,03 & $\mathrm{ab}$ & 85,33 & $\mathrm{~B}$ \\
4. MI11 & 3,17 & $\mathrm{~b}$ & 3,83 & $\mathrm{ab}$ & 4,93 & $\mathrm{ab}$ & 101,22 & $\mathrm{AB}$ \\
5. HO4 & 3,80 & $\mathrm{ab}$ & 5,67 & $\mathrm{a}$ & 3,87 & $\mathrm{ab}$ & 106,00 & $\mathrm{AB}$ \\
6. MA5 & 4,30 & $\mathrm{ab}$ & 3,93 & $\mathrm{ab}$ & 4,28 & $\mathrm{ab}$ & 111,33 & $\mathrm{AB}$ \\
7. MA1 & 3,30 & $\mathrm{~b}$ & 3,00 & $\mathrm{~b}$ & 3,90 & $\mathrm{ab}$ & 91,11 & $\mathrm{AB}$ \\
8. MI12 & 4,70 & $\mathrm{ab}$ & 4,03 & $\mathrm{ab}$ & 2,83 & $\mathrm{~b}$ & 100,00 & $\mathrm{AB}$ \\
\hline
\end{tabular}

Obs: médias acompanhadas de mesma letra na coluna e na linha (somente letras minúsculas) são estatisticamente semelhantes entre si segundo o teste de Tukey ao nível de 5\% de probabilidade

No experimento em pré-emergência do pepino, a testemunha apresentou um certo efeito inibitório no acúmulo de biomassa verde em relação ao tratamento 6 (MA5) como evidenciado na tabela 10. Pode-se atribuir este fato a um sensível estímulo no acúmulo de biomassa do tratamento 6 (MA5). Apesar de ter demonstrado um maior acúmulo de massa verde, a área folhar deste tratamento foi estimada como uma das menores, isto demonstra um provável desequilíbrio estrutural da planta onde poderia ter havido um espessamento de caule ou um acúmulo anormal de líquidos pela planta. Na literatura tem sido relatado efeito 
estimulante de compostos produzidos por actinomicetos sobre as plantas. Heisey et al. (1985) encontraram que 19\% dos 347 isolados estudados em Cucumis sativus, $10 \%$ em Echinochloa crusgalli e 2\% em Lepidium sativum provocaram estímulo no crescimento destas plantas. A alelopatia é definida por alguns autores como algum efeito prejudicial ou benéfico, direto ou indireto, de uma planta (ou microorganismo) em outra através da produção de compostos químicos que são liberados no ambiente comum (Rice, 1984). Justificando assim alguns resultados obtidos nesta pesquisa.

A área folhar não foi significativamente afetada pelo teste de Tukey a 5\% de probabilidade, porém na análise de variância foi detectado significância estatística $(\mathrm{P} \leq 0,1)$. Observa-se pela tabela 10 no parâmetro área folhar que os tratamentos 5, 6 e 8 reduziram a média de área folhar de forma mais intensa que os demais tratamentos, apesar da não significância estatística destes tratamentos através do teste de Tukey ao nível de 5\% de probabilidade. 
Tabela 10. Peso da matéria verde (PV) e área folhar (AF) das plantas de pepino em função dos tratamentos do experimento de pré-emergência

\begin{tabular}{lrlc}
\hline Tratamentos & Peso da matéria verde (PV) & Área folhar (AF) \\
\hline 1. testemunha & 87,00 & B & 8,20 \\
2. branco & 95,67 & AB & 9,43 \\
3. MI15 & 95,67 & AB & 8,01 \\
4. MI11 & 95,83 & AB & 9,29 \\
5. HO4 & 95,83 & AB & 6,40 \\
6. MA5 & 98,61 & A & 6,40 \\
7. MA1 & 97,06 & AB & 9,21 \\
8. MI12 & 95,67 & AB & 6,37 \\
\hline \multicolumn{2}{l}{ Obs: médias acompanhadas de mesma letra na coluna são estatisticamente semelhantes entre si segundo o } \\
teste de Tukey ao nível de 5\% de probabilidade
\end{tabular}

$\mathrm{Na}$ tabela 11 não são observadas diferenças significativas entre os tratamentos e as doses. Verifica-se que, na concentração 1:0, não houve tendência de nenhum tratamento em pré-emergência alterar significativamente a área folhar do sorgo, apesar dos isolados MI15 e MA1 mostrarem uma tendência de estímulo na produção de área folhar. Na concentração de 1:1 verifica-se nitidamente um efeito estimulante do isolado MI11 e na concentração 1:3 um efeito inibitório do tratamento MI15. 
Tabela 11. Área folhar das plantas de sorgo em função dos tratamentos com os isolados e das doses utilizadas no experimento em pré-emergência

\begin{tabular}{lccc}
\hline \multicolumn{1}{c}{ Tratamentos } & \multicolumn{3}{c}{ Doses } \\
& $\mathbf{1 : 0}$ & $\mathbf{1 : 1}$ & $\mathbf{1 : 3}$ \\
\hline 1. testemunha & 4,43 & 4,43 & 4,43 \\
2. branco & 3,33 & 7,57 & 4,47 \\
3. MI15 & 7,67 & 4,13 & 3,20 \\
4. MI1 & 5,43 & 8,00 & 5,37 \\
5. HO4 & 4,17 & 4,20 & 5,10 \\
6. MA5 & 4,07 & 4,70 & 5,50 \\
7. MA1 & 7,03 & 5,70 & 6,27 \\
8. MI12 & 4,60 & 4,83 & 6,13 \\
\hline Apesar do teste F ser significativo, não foram encontradas diferenças entre as médias pelo teste de Tukey &
\end{tabular}

A avaliação do peso da matéria verde das plantas de picão-preto, independente da interação com a dose, apresentado na tabela 12 revelou diferenças estatisticamente significativas pela análise de variância ao nível de $10 \%$ de probabilidade. Sendo assim, o teste de Tukey feito a 5\% não mostrou diferenças na comparação entre as médias. No entanto, observa-se que os tratamentos 5 e 6 (HO4 e MA5) afetaram o acúmulo de matéria verde nas plantas, repetindo os resultados do screening secundário (tabela 4) onde estes tratamentos exerceram efeito em pré-emergência sobre o pepino e o sorgo respectivamente. Os efeitos do tratamento 6 (MA5) também foram observados na inibição do peso da matéria verde no experimento em pós-emergência do sorgo (tabela 7), indicando algum potencial alelopático. A planta daninha picão-preto é uma das espécies dicotiledôneas mais importantes nas áreas agrícolas brasileiras, especialmente na cultura da soja. Alternativas de controle para esta planta daninha seriam fundamentais no auxílio aos métodos de manejo atuais. 
Tabela 12. Peso da matéria verde das plantas de picão-preto em função dos tratamentos com os isolados independentemente da dose utilizada no experimento em pré-emergência

\begin{tabular}{lc}
\hline \multicolumn{1}{c}{ Tratamentos } & Peso da matéria verde (PV) \\
\hline 1. testemunha & 29,33 \\
2. branco & 36,44 \\
3. MI15 & 35,11 \\
4. MI1 & 35,56 \\
5. HO4 & 25,11 \\
6. MA5 & 26,00 \\
7. MA1 & 37,33 \\
8. MI12 & 37,56 \\
\hline Apesar do teste F ser significativo, não foram encontradas diferenças entre as médias pelo teste de Tukey \\
ao nível de 5\% de probabilidade
\end{tabular}

$\mathrm{Na}$ tabela 13 pode ser observado que no experimento em préemergência a área folhar do capim-colchão foi significativamente afetada, independente da interação com a dose, pelos compostos dos isolados e pelo meio de cultura. Observa-se que o tratamento 6 (MA5) e a testemunha afetaram de forma significativa a área folhar em relação ao tratamento 3 (MI15), embora estes tratamentos foram semelhantes aos demais tratamentos, inclusive a testemunha branco. Podemos atribuir este fato a um efeito inibitório do tratamento 6 (MA5) somados a um estímulo no crescimento do tratamento 3 (MI15). 
Tabela 13. Área folhar das plantas de capim-colchão em função dos tratamentos com os isolados independentemente da dose utilizada no experimento em pré-emergência

\begin{tabular}{lcl}
\hline \multicolumn{1}{c}{ Tratamentos } & Área folhar (AF) \\
\hline 1. testemunha & 2,67 & $\mathrm{~B}$ \\
2. branco & 4,06 & $\mathrm{AB}$ \\
3. MI15 & 4,98 & $\mathrm{~A}$ \\
4. MI11 & 3,50 & $\mathrm{AB}$ \\
5. HO4 & 3,57 & $\mathrm{AB}$ \\
6. MA5 & $3,01 \quad \mathrm{~B}$ \\
7. MA1 & $3,90 \mathrm{AB}$ \\
8. MI12 & $3,14 \quad \mathrm{AB}$ \\
\hline Obs: médias acompanhadas de mesma letra na coluna são estatisticamente semelhantes entre si segundo o
\end{tabular}

Novas pesquisas devem dar continuidade ao presente trabalho, principalmente através de fracionamento e isolamento dos compostos, uma vez que fica claro por esta pesquisa que fontes biológicas (actinomicetos) com potencial de produção de fitotoxinas foram encontradas. Para a continuidade do trabalho, instrumentação completamente automatizada é necessária, tais como cromatografia líquida, espectrometria de massa e ressonância magnética nuclear (Bailey et al. 2000), que não foi o objetivo desta pesquisa. A automação também é necessária pois alguns produtos naturais são altamente tóxicos a mamíferos (Abbas et al. 1996). Sendo assim, é prudente que futuras pesquisas com estes compostos tenham preocupação nos aspectos toxicológicos destas fitotoxinas. 


\section{CONCLUSÕES}

a) A metodologia utilizada nesta pesquisa para seleção de isolados de actinomicetos com potencial de produção de fitotoxinas é adequada, e pode ser utilizada em programas de seleção de actinomicetos com potencial de produção de compostos alelopáticos para o controle de plantas daninhas.

b) O meio de cultura para testes preliminares de seleção de isolados (teste de germinação) deve conter no máximo 33\% de solução proveniente dos isolados pois acima desta concentração o potencial osmótico da solução pode interferir na interpretação dos resultados.

c) Actinomicetos que habitam sistemas de produção e/ou vegetação nas condições de solos tropicais brasileiros apresentam grande potencial de produção de novas fitotoxinas $(18,5 \%)$, especialmente em sistemas de produção da cultura da cana-de-açúcar, onde 55,6\% dos actinomicetos testados apresentam produção de alguma fitotoxina inibitória do crescimento das plantas.

d) Nenhum dos actinomicetos estudados produziu concentrações de fitotoxinas no meio de cultura suficiente para uso direto como agente de controle, porém têm potencial de utilização no desenvolvimento de novas moléculas de herbicidas. 
e) A descoberta de novos compostos químicos, com mecanismos de ação que resulta em propriedades herbicidas, tem grande potencial à partir de actinomicetos, embora estes microrganismos possam também produzir compostos com efeitos estimulantes no crescimento das plantas.

f) Em futuras pesquisas desta natureza é importante desenvolver formulações que facilitem a penetração dos possíveis aleloquímicos pela folha das plantas, e que proporcionem maior estabilidade quando aplicadas no solo. 


\section{REFERÊNCIAS BIBLIOGRÁFICAS}

ABBAS, H.K.; TANAKA, T.; DUKE, S.O. Fumonisin and AAL-toxin-induced disruption of sphingolipid metabolism with accumulation of free sphingoid bases: involvement in plant disease. Plant Physiology, n.106, p.1085-1093, 1994.

ABBAS, H.K.; DUKE, S.O.; SHIER, W.T.; DUKE, M.V. Inhibition of ceramide synthesis in plants by phytotoxins. In: UPADHYAY, R.K. Advances in Microbial Toxin Research and Its Biotechnological Exploitation. London: Kluwer Academic/Plenum Press, 2002. 288p.

ABBAS, H.K.; DUKE, S.O.; SHIER, W.T.; RILEY, R.T.; KRAUS, G.A. The chemistry and biological activities of the natural products AAL-toxin and the fumonisins. In: SINGH, B.R.; TU, A.T. Natural Toxins 2. Structure, Mechanism of Action, and Detection. Advances in Experimental Medicine and Biology, v.391, p.293-308, 1996.

AYER, S.W.; ISAAC, B.G.; KRUPA, D.M.; CROSBY, K.E.; LETRENDE, L.J.; STONARD, R.J. Herbicidal compounds from microorganisms. Pesticide Science, n.27, p.221-223, 1989. 
BAILEY, N.J.C.; STANLEY, P.D.; HADFIELD, S.T.; LINDON, J.C.; NICHOLSON, J.K. Mass spectrometrically detected directly coupled high performance liquid chromatography/nuclear magnetic resonance spectroscopy/mass spectrometry for the identification of xenobiotics metabolites in maize plants. Rapid Communications in Mass Spectrometry, v.14, p.679-684, 2000.

BAYER, E.; GUGEL, K. H.; HAGELE, K.; HAGENMAIH, H.; JESSIPOW, S.; KONIG, W.A.; ZAHNER, H. Metabolites of microorganisms 98. Phosphinothricin and Phosphinothricyl-alanylalanine. Helvetica Chimica Acta, v.55, n.1, p.224-239, 1972.

BLAND, J.M.; EDWARDS, J.V.; EATON, S.R.; LAX, A.R. Potential of natural peptide compounds as leads for novel pesticides. Pesticide Science, n.39, p.331-340, 1993.

BOBYLEV, M.M.; BOBYLEVA, L.I.; STROBEL, G.A. Synthesis and bioactivity of analogs of maculosin, a host-specific phytotoxin produced by Alternaria alternata on spotted knapweed (Centauria maculosa). Journal Agricultural and Food Chemistry, n.44, p.3940-3964, 1996.

CHEN, D.Z.; PATEL, D.V.; HACKBARTH, C.J. Actinonin, a naturally occurring antibacterial agent, is a potent deformylase inhibitor. Biochemistry, n.39, p.1256-1262, 2000.

CHOUDHARY, M.I.; ATTA-UR-RAHMAN Bioactivity-guided phytochemicals from medicinal plants. Royal Society of Chemistry - Special Publication, n.200, p.41-52, 1997. 
CHRISTOFFOLETI, P.J.; DOURADO NETO, D. Manejo integrado de plantas daninhas sob pivô central. In: ZAMBOLIM, L. (Ed.) Manejo integrado fitossanidade: cultivo protegido, pivô central e plantio direto. Viçosa, 2001. p.625-654.

COBLE, H.D. Weed management tools and their impact on the agro-ecosystem. INT. WEED CONTROL CONGRESS, 2., Copenhagen, 1996. Proceeding p.1143-1146.

CONSTANT, H.; BEECHER, C.W.W. A method for the dereplication of natural product extracts using electrospray HPLC/MS. Natural Product Letters, v.6, p.193-196, 1995.

DAYAN, F.E.; RIMANDO, A.M.; TELLEZ, M.R.; SCHEFFLER, B.E.; ROY, T.; ABBAS, H.K. The mechanism of action of the fungal phytotoxin 2,5anhydro-D-glucitol requires bioactivation by glycolytic enzymes. Weed Science Society of America Abstracts, v.42, p.49, 2002.

DeFRANK, J.; PUTNAM, A.R. Screening procedures to identify soil-borne Actinomycetes that can produce herbicidal compounds. Weed Science, v.33, p.271-274, 1996.

DIRK, L.M.A.; WILLIAMS, M.A.; HOUTZ, R.L. Eukaryotic peptide deformylases, nuclear-encoded and chloroplast-targeted enzymes in Arabidopsis. Plant Physiology, n.127, p.97-107, 2001.

DUKE, S.O. Microbially produced phytotoxins as herbicides - a perspective. cap. 17, p. 287-304, 1997. 
DUKE, S.O.; DAYAN, F.E. ROMAGNI, J.G.; RIMANDO, A.M. Natural products as sources of herbicides: current status and future trends. Weed Research, v. 40, n. 1, p. 99-111, 2000a.

DUKE, S.O.; DAYAN, F.E.; RIMANDO, A.M. Natural products and herbicide discovery. In: COBB, A.H.; KIRKWOOD, R.C. Herbicides and their mechanisms of action. Sheffield: Academic Press, 2000b. p.105-133.

DUKE, S.O.; RIMANDO, A.M.; DAYAN, F.E. Phytochemicals as Bioactive Agents. In: BIDLACK, W.R.; OMAYE, S.T.; MESKIN, M.S.; TOPHAM, D.K.W. Strategies for the discovery of bioactive phytochemicals. Lancaster: Technomic Publishing, 2000c. p.1-20.

DUKE, S.O.; DAYAN, F.E.; RIMANDO, A.M.; SCHRADER, K.K.; ALIOTA, G.; OLIVA, A.; ROMAGNI, J.G. Chemicals from nature for weed management. Weed Science, n. 50, p. 138-151, 2002.

EDWARDS, J.V.; DAILEY, O.D.; BLAND, J.M.; CUTLER, H.G. Approaches to structure-function relationships for naturally occurring cyclic peptides. American Chemical Society Symposium Ser., n.380, p.35-56, 1988.

FAO Production Yearbook. v. 51. 1997. 241p.

FELSKE, A.; RHEIMS, H.; WOLTERNICK, A.; STRACKEBRANDT, E.; AKKERMANS, A.D. Ribosome analysis reveals prominent activity of an uncultured member of class Actinobacteria in grassland soils. Microbiology, n.143, p.2983-2989, 1997. 
GOTTLIEB, D. General consideration and implications of the actinomycetales. In: SYRES, G.; SKINNER, F.A. Actinomycetales: characteristics and practical importance. London: Academic Press, 1973. p. 1-10.

HALL, J.C.; VAN LEER, L.L.; MILLER, S.D. Future research directions for weed science. Weed Technology, v. 14, n. 3, p. 647-658, 2000.

HARRISON, S.K.; LOUX, M.M. Chemical weed management. In: SMITH, A. (Ed.). Handbook of weed management systems. New York: Marcell Dekker, cap. 5, 1995. p.101-154.

HEISEY, R.M.; PUTNAM, A.R. Herbicidal effects of geldanamycin and nigericin, antibiotics from Streptomyces hygroscopicus. Journal of Natural Products, v.49, n.5, p.859-865, 1986.

HEISEY, R.M.; DEFRANK, J.; PUTNAM, A.R. A survey of soil microorganisms for herbicidal activity. In: THOMPSON, A.C. Chemistry of allelopathy: biochemical interactions among plants, Washington: S.N., 1985. p.337-349.

HEISEY, R.M.; MISHRA, S.K.; PUTNAM, A.R. Production of herbicidal and insecticidal metabolites by soil microorganisms. American Chemical Society Symposium Ser., n.380, p.68-78, 1988.

HOOK, D.J.; PACK, E.J.; YACOBUCCI, J.J.; GUSS, J. Approaches to automating the dereplication of bioactive natural products - the key step in high throughput screening of bioactive materials from natural sources. Journal of Biomolecular Screening, v.2, p. 145-152, 1997. 
LINDON, J.C.; NICHOLSON, J.K.; WILSON, I.D. The development and application of coupled HPLC-NMR spectroscopy. Advances in Chromatography, v.124, p. 315-382, 1996.

MENENDEZ, J.; DE PRADO, R. La resistencia de las malas hiervas a los herbicidas. Phytoma, v. 94, p. 43-50, 1998.

MISHRA, S.K.; WHITEHACK, C.J.; PUTNAM, A.R. Herbicidal properties of metabolites from several genera of soil microorganisms. Weed Science, v.36, p. 122-126, 1988.

OLIVEIRA, M.F. Comportamento de herbicidas no ambiente. In: OLIVEIRA JÚNIOR, R.; CONSTANTIN, J. (Coord.) Plantas daninhas e seu manejo. Guaíba: Agropecuária, 2001. p.316-355.

PEREIRA, J.C. Ecologia da comunidade bacteriana em solos de cerrado. Itaguaí, 1995. 172p. Tese (Doutorado) - Universidade Federal Rural do Rio de Janeiro.

PEZZUTO, J.M.; BEECHER, C.W.W.; FONG, H.H.S. Recent studies on biologically active natural products. In: ATTA-UR-RAHMAN; CHOUDHARY, M.I. New trends in natural products chemistry. Netherlands: Hardwod Acad. Publ., 1998. p.94-107.

PIMM, S.L.; RUSSELL, G.J.; GITTLEMAN, J.L.; BROOKS, T.M. The future of biodiversity. Science, n.269, p.347-350, 1995.

RICE, E. L. Allelopathy. 2 ed., Orlando: Academic Press, 1984. 422p. 
RIMANDO A.M.; DAYAN, F.E.; CZARNOTA, M.A.; WESTON, L.A.; DUKE, S.O. A new photosystem II electron transfer inhibitor from Sorghum bicolor. Journal of Natural Products, n.61, p.927-930, 1998.

RIMANDO A.M.; DAYAN, F.E.; MIKELL, J.R.; MORAES, R.M. Phytotoxic lignans of Leucophyllum frutescens. Natural Toxins, n.7, p.39-43, 1999.

ROMAGNI, J.G.; MEAZZA, G.; NANYAKKARA, N.P.D.; DAYAN, F.E. The phytotoxic lichen metabolite, usnic acid, is a potent inhibitor of plant $p$ hydroxyphenylpyruvate dioxygenase. FEBS Letters, n.480, p.301-305, 2000.

SAS Statistical Analysis Systems. SAS User's Guide. Cary, NC: Statistical Analysis Systems Institute, 1995. 1028p.

SCHRADER, K.K.; DUKE, S.O.; KINGSBURY, S.K.; TUCKER, C.S.; DUKE, M.V.; DIONIGI, C.P.; MILLIE, D.F.; ZIMBA, P.V. Evaluation of ferulic acid for controlling the musty-odor cyanobacterium, Oscillatoria perornata, in aquaculture ponds. Journal of Applied Aquaculture, n.10, p.1-16, 2000.

SEVERINO, F.J. Adubação verde: efeitos supressivos sobre a infestação de plantas daninhas e seletividade de herbicidas. Piracicaba, 2001. 120p. Dissertação (Mestrado) - Escola Superior de Agricultura “Luiz de Queiroz", Universidade de São Paulo.

SINDAG - Sindicato das Indústrias de Defensivos Agrícolas http://www.sindag.com.br/new/noticias/interna.php?cod=420. (19 jun. 2004). 
STONARD, R.J.; MILLER-WIDEMAN. Herbicides and plant growth regulators. In: GODFREY, C.R.A. (Ed.). Agrochemicals from natural products. New York: Marcel Dekker, 1995. cap. 6. p. 285-310.

SUGAWARA, F. Phytotoxins as potential herbicides. In: NARWAL, S.S.; HOAGLAND, R.E.; DILDAY, R.H.; REIGOSA, M.J. Allelopathy in Ecological Agriculture and Forestry. Amsterdam: Kluwer Academic Publishers, 2000. p.113-128.

TANAKA, T.; HATANO, K.; WATANABE, M. Isolation, purification and identification of 2,5-anhydro-d-glucitol as a phytotoxin from Fusarium solani. Journal of Natural Toxins, n.5, p.317-329, 1996.

UMEZAWA, H. Index of antibiotics from Actinomycetes. Tóquio: Universidade de Tóquio, v.1, 1967.940p.

WAKSMAN, S.A. The actinomycetes: their nature, occurrence, activities, and importance. Mass.: Chronic. Bot. CO., 1950. 230p.

WILliAMS, S.T.; WELlingTON, E.M.H. Actinomycetes. In: PAGE, A.L.; MILLER, R.H.; KEENEY, D.R. (Ed.). Methods of soil analysis. 2. ed. Madison: ASA/SSSA, 1982. p. 964-987. (ASA. Agronomy, 9)

ZIMDAHL, R.L. Weed Science: a plea for thought. Fort Collins: USDA, Cooperative State Research Service. A Symposium Reprint, 1991. 34 p. 